URBANISMO

ISSN 0717-5051

http://revistas.uchile.cl/index.php/RU/index
Definiciones y espacialidades de barrio -arrabal, parroquia, districto y suburbio- y términos afines. Recife: los barrios centrales y del 'Conjunto Urbano de Casa Forte'

Definitions and spatialities - slum neighborhood, parish, district and suburb - and related terms. Recife: the central districts and the 'Conjunto Urbano de Casa Forte'

\title{
Definiciones y espacialidades de barrio - arrabal, parroquia, districto y suburbio- y términos afines. Recife: los barrios centrales y del 'Conjunto Urbano de Casa Forte'
}

Definitions and spatialities - slum neighborhood, parish, district and suburb - and related terms. Recife: the central districts and the 'Conjunto Urbano de Casa Forte'

\section{Sandra Leao}

\section{Filiación}

Agencia Estatal de Planeamiento e Investigaciones de Pernambuco (CONDEPE/FIDEM), Brasil.

\section{Resumen}

La definición de barrio y las cuestiones que lo limitan corresponden al eje central de este estudio. Los barrios son líneas en un plano, pero líneas llenas de significados que contienen, sobre el casco físicogeográfico, diversas matrices socio-económicas e histórico-culturales que los hacen únicos. Los dos conjuntos de barrios estudiados en esta investigación, son significativos polígonos de Recife, parte de la esencia misma de la ciudad, en un sentido no sólo de identidad íntegra y plena, sino también de complementariedad y solidaridad. Son límites abstractos en un sentido, concretísimos en otro, cuya discusión traspasa, y mucho, el ámbito de una tesis. El barrio siempre es tema del orden del día en el planeamiento urbano actual, es, antes de todo, la escala del cotidiano, del (re) conocimiento del ciudadano delante del espacio que habita.

\section{Palabras clave}

Concepto de Barrio, arrabal, parroquia, suburbio histórico, Recife.

\begin{abstract}
The districts are just lines on paper. However, the lines are full of meaning, they have in the physicalgeographical support many shades of socio-economic, historical and cultural, that make them unique. Moreover, these two sets of neighborhoods that are case studies of Recife in this research, even merge with the essence of the city, a sense of identity not only to complementarity and solidarity. Limits in the abstract, concrete in another, whose analysis is beyond the scope and much of the argument of a thesis will always be on the agenda of the current urban planning, the district first and foremost is the scale of everyday life, recognizing people for living spaces. The definition of neighborhoods and the issues that define it are the focus of this research.
\end{abstract}

\section{Key-words}

Neighborhood, parish, historic district, Recife.

\section{Sumario}

Introducción

1.-Investigación semántica de la palabra barrio y términos afines (arrabal, parroquia, districto, suburbio).

1.1. Una mirada histórica sobre el barrio en el presente

1.2. - Una mirada geográfica sobre el barrio en el presente

2.-Denominaciones, definiciones y espacialidades: diccionarios técnicos, diccionarios de lenguas, entradas virtuales, enciclopedias, un 'popurri'.

3.- ¿Lo que define un barrio?

3.1. ¿Una nomenclatura?

3.2. ¿Un límite físico-espacial?

3.3. ¿Sus espacios libres?

3.4. ¿El curso del río, su tierra baja o 'ventanas' que se abren para él?

3.5. ¿Una forma, un contenido y una escala urbana?

43 
REVISTA DE

URBANISMO

ISSN 0717-5051

http://revistas.uchile.cl/index.php/RU/index
Definiciones y espacialidades de barrio -arrabal, parroquia, districto y suburbio- y términos afines. Recife: los barrios centrales y del 'Conjunto Urbano de Casa Forte'

Definitions and spatialities - slum neighborhood, parish, district and suburb - and related terms. Recife: the central districts and the 'Conjunto Urbano de Casa Forte'

4.-La Ciudad de Recife: los barrios centrales y los barrios del Conjunto Urbano de Casa Forte

4.1. Los límites naturales

4.2. Su historia urbana de ocupación

4.3. La expansión urbana en dirección al interior de la planicie

4.4. Los primeros aglomerados/pueblos

4.5. Los barrios de Recife, en particular los barrios centrales y los barrios del Conjunto Urbano de Casa Forte hoy. Consideraciones finales

Bibliografía

\section{Introducción}

El presente escrito, cuyo título se rebate en su propio contenido, tiene como eje central la investigación de conceptos, nombres y respectivas equiparaciones en lo espacial, en la intención de asociar la escala del barrio al arrabal, la parroquia y el suburbio histórico. Se intenta probar que, a pesar de las diferentes nomenclaturas, siempre hay referencia a la misma escala del urbano. Se tiene como objeto de estudio dos conjuntos de barrios: los barrios del centro de Recife, y los barrios del Conjunto Urbano de Casa Forte, así conocidos los seis barrios en la margen izquierda del río Capibaribe en sus tierras bajas.

Se investiga, por otro lado, la historia de Recife, y cómo esa escala estuvo y está presente en la regulación de su tejido urbano, sea como ingenio, parroquia, arrabal, sector censitario, barrio o Región Político-Administrativa. Es el tema de la tesis de Máster y Tesis de Doctorado de la autora, eje central de sus investigaciones también fuera de la academia.

El barrio, escala esencial para la existencia y reconocimiento del espacio urbano, de orígen histórico en la escala de la parroquia, del arrabal y del suburbio histórico, encuentra en la transición de ingenio para barrio, que va a tomar cuerpo y significado. Optar por los barrios centrales y por los barrios del Conjunto Urbano de Casa Forte como estudios de caso no fue casual. Por lo contrario, a partir del planteo de ideas establecido en el cuerpo teórico, aparece lo más primario, original y auténtico del Recife de otrora, aunque con varios trazos de cambios posteriores. Primero, se sintetiza la génesis de Recife, su inicio y vocación, con tiempos sobrepuestos, dando cuenta en su casco histórico de huellas de esos primeros tiempos y primeros barrios.

Con un sentido de complementariedad e identidad urbana de una urbe que empieza a desarrollarse y expandirse, está el otro flanco, fuerte y dinamizador, de su carácter anfibio y complementario a sus servicios en el centro portuario. Son los barrios de la fecunda tierra baja del Capibaribe, en su margen izquierda, desde siempre sede de residencia de la aristocracia recifense, después ingleses, que ahí hicieron y todavía hacen su suburbio verde, su cultura, su simbolismo, los secretos locales para los que son de allí y allí se reconocen y son reconocidos.

Barrio es tema del orden del día cuando se discute nuevos conceptos de Regiones Metropolitanas y municipios componentes, límites, unidades territoriales y unidades administrativas. El barrio se inserta en esa nueva espacialidad, como parte de ese sistema que, aun presente un concepto y una nomenclatura, se refiere y envuelve esta nueva urbanidad que empieza a surgir en el siglo XXI.

No se podría afirmar su persistencia en el futuro, pero sí como escala y esencia. Es sobre esas cuestiones que trata este escrito.

44 
URBANISMO

ISSN 0717-5051

http://revistas.uchile.cl/index.php/RU/index
Definiciones y espacialidades de barrio -arrabal, parroquia, districto y suburbio- y términos afines. Recife: los barrios centrales y del 'Conjunto Urbano de Casa Forte'

Definitions and spatialities - slum neighborhood, parish, district and suburb - and related terms. Recife: the central districts and the 'Conjunto Urbano de Casa Forte'

\title{
1.-Investigación semántica de la palabra barrio y términos afines (arrabal, parroquia, districto, suburbio).
}

\section{1.-Una mirada histórica sobre el barrio en el presente}

- Barrio como parroquia

Según Lefebvre, el barrio corresponde al ámbito natural de la vida social y es la unidad social a la escala humana.

\begin{abstract}
"La parroquia no sólo tenía una existencia religiosa, sino también una existencia civil y política. No existía lo que llamamos 'estado civil; los bautismos, los casamientos y las muertes se inscribían en los registros parroquiales; los agrupamientos y asociaciones seculares se organizaban alrededor del aparato eclesiástico; las cofradías estaban relacionadas con las corporaciones y con los gremios y oficios, y por lo tanto, con la actividad económica. (...)". ${ }^{1}$
\end{abstract}

La parroquia constituía la más pequeña célula eclesiástica y administrativa. La línea jerárquica puebloparroquia-villa-ciudad, según Murillo Marx, empezaba en la aspiración de un pueblo a la categoría de parroquia, que significaba tener una capilla curada reconocida por la corona portuguesa.

Un pueblo de determinado porte aspiraría constituir una parroquia o, denominación que prevaleció entre nosotros, una parroquia. Después tal parroquia va a anhelar la autonomía municipal que, alcanzada, contendrá en su símbolo la picota, y en su casa Cámara y cadena. Símbolo y sede del municipio que deberá componerse con el templo preexistente. El punto privilegiado topográfico ya estará ocupado, el área más prestigiada del lugar definida, el largo principal constituido...

Por medio de la elevación de la categoría de simple capilla, o capilla curada, a otro nivel, nivel antes de todo de naturaleza religiosa, ahora, con todo, llena de una naturaleza civil explícita: la erección del lugarejo, de la capilla, de la parroquia, cuyo nombre cotidiano tradicional fue parroquia y que constituía el módulo de la organización eclesiástica, como de su unidad territorial". ${ }^{2}$

No se olvidará que la iglesia católica representaba aún la centralidad de aquella parroquia, centralidad que no se daba desde el punto de vista físico, como centralidad espacial-geométrica, sino como centralidad de reconocimiento y atractividad del barrio.

\begin{abstract}
"Los barrios, en el tratamiento cotidiano, no son bien definidos ni siguen padrones rígidos. En tiempos antiguos, que preceden el descubrimiento del Brasil, correspondían a la organización de las parroquias de la Iglesia Católica. Era fácil hacer distinciones: cada parroquia tenía su templo y su santo, se organizaba en torno de ellos y de otras facilidades como ferias y mercados. Fue esa la tradición traida de Portugal. En general, en los centros urbanos más antiguos, los barrios son más fáciles de identificar. Ellos tienden a ser más grandes y más imprecisos cuando se va en dirección a las periferias". ${ }^{3}$
\end{abstract}

- Barrio como módulo militar

El barrio también puede ser considerado como unidad militar, pues las tropas de Ordenanza estaban organizadas de acuerdo con la división de los barrios.

"La división de las parroquias venía formalizar la constitución de los barrios. Unida la Iglesia al Estado, constituían las parroquias una división oficial de los barrios, completando de ese modo su definición. Estaban

LEFEBVRE, 1971, p. 19-203, cap. XIV - Barrio y vida de barrio.

MARX, 1991, pp. 12-14, 18, 26, 52,62, Grifos mios.

SANTOS, 1988 , p. 116.

45

Revista de Urbanismo N²6 - Junio de 2012 Departamento de Urbanismo - FAU - Universidad de Chile 
REVISTA DE

URBANISMO

ISSN 0717-5051

http://revistas.uchile.cl/index.php/RU/index
Definiciones y espacialidades de barrio -arrabal, parroquia, districto y suburbio- y términos afines. Recife: los barrios centrales y del 'Conjunto Urbano de Casa Forte'

Definitions and spatialities - slum neighborhood, parish, district and suburb - and related terms. Recife: the central districts and the 'Conjunto Urbano de Casa Forte'

en el área urbana a una distancia limitada de ruta, en relación a un punto de reunión religiosa, civil y militar. Eran divisiones religiosas pero también de sentido administrativo para casamientos, bautizados, óbitos, y eran también divisiones militares, pues en ellas estaba basada la organización de las tropas de Ordenanza. Era por lo tanto una división básica de la población". ${ }^{4}$

- $\quad$ Barrio como unidad espacial y social del universo caipira paulista

En el interior paulista investigado por Antonio Candido, el barrio está asociado a un territorio definido y a un sentimiento de localidad.

\begin{abstract}
"Barrio siempre aparece como división administrativa de la parroquia, que lo es a la vez de la villa. Esta era sede de la Cámara y Parroquia y cabeza de todo el territorio, casi siempre vasto; la parroquia suponía un núcleo de habitación compacta y una iglesia con sacerdote, generalmente coadjutor del vicario de la parroquia; el barrio era división que incluía los moradores escasos, con su sencilla capilla y, en ocasiones, cementerio. (...) Pero más allá de determinado territorio, el barrio se caracteriza por un segundo elemento, el sentimiento de localidad existente en sus habitantes, y cuya formación depende no sólo de la posición geográfica, sino también del intercambio entre las familias y las personas, llevando, por así decir el esqueleto topográfico. -Qué es barrio?- pregunté cierta vez a un viejo caboclo, y su respuesta expresó en una frase lo que se viene exponiendo aquí: - Barrio es una pequeña nación. - Entiéndase: la porción de tierra a la que los moradores tienen consciencia de pertenecer, formando una cierta unidad diferente de las otras. (...) Es la unidad en que se ordenan las relaciones básicas de la vida del campo, rudimentarias como él. Es un mínimo social, equivalente, en el plano de las relaciones, al mínimo vital representado por la dieta". 5
\end{abstract}

- Barrio como escala de la dimensión política, del activismo de barrio.

Según Marcelo José es en la escala del barrio que se reclama por escuelas, puestos de salud, pavimentación de calles; diferente de la escala de la calle y de la escala del lote.

"El barrio es un referencial directo $y$ decisivo, pues define territorialmente la base social de un activismo, de una organización, aglutinando grupos y a veces clases diferentes (en niveles variables de acomodación y tensión). Es el escenario cotidiano, arena de lucha más inmediata, referencial organizativo básico y catalizador simbólico. (...) Las personas inconsciente o conscientemente siempre 'demarca' sus barrios a partir de marcos referenciales que ellas tienen y, ciertamente, otras antes que ellas, produciendo una herencia simbólica que pasa de generación a generación. Los límites del barrio pueden ser imprecisos, pueden cambiar un poco de persona para persona. Pero si esa variación es muy grande, difícilmente se estará delante de un barrio, porque difícilmente habrá un soporte para una identidad razonablemente compartida, o un legado simbólico suficientemente expresivo". ${ }^{6}$

- Barrio como Unidad Urbana del Planeamiento actual

En la ciudad de São Paulo hubo una experiencia en la elaboración de Planes de Barrio como sub-planes de los Planes Regionales de la ciudad, constituyendo el modulo mínimo del planeamiento urbano.

"El Plan de Barrio es un instrumento para su inserción en el planeamiento de la ciudad como un todo. A través de él y del Plan Regional que reune los Planes de Barrio de su sub-ayuntamiento, es posible comprender el juego especulativo en que estamos metidos. (...) La discusión de los Planes Regionales y de los Planes de Barrio crea un nuevo escenario de debate público, donde los intereses en conflicto pueden presentarse -aunque los intereses especulativos, avergonzados de los valores antisociales que defienden, prefieren la ación en los bastidores, como hemos visto recientemente en la aprobación de las enmiendas especulativas del Plan Director". 7

REIS FILHO, 2000, pp. 153-155, Grifos mios.

CANDIDO, 2001, pp. 44-47, 51-56.

SOUZA, 1989, pp. 139-140, 144, 149-150, 153.

CAMPOS FILHO, 2005, p. 81, 97.

46

Revista de Urbanismo N²6 - Junio de 2012
46

Departamento de Urbanismo - FAU - Universidad de Chile 
REVISTA DE

URBANISMO

ISSN 0717-5051

http://revistas.uchile.cl/index.php/RU/index
Definiciones y espacialidades de barrio -arrabal, parroquia, districto y suburbio- y términos afines. Recife: los barrios centrales y del 'Conjunto Urbano de Casa Forte'

Definitions and spatialities - slum neighborhood, parish, district and suburb - and related terms. Recife: the central districts and the 'Conjunto Urbano de Casa Forte'

Para Jorge Wilheim el barrio constituye hoy:

\begin{abstract}
"la unidad urbana, la representación más legítima de la espacialidad de su población, y no es por casualidad que São Paulo cuenta con 900 'sociedades de habitantes', también conocidas como 'sociedades de amigos del barrio', cuya territorialidad es facilmente establecida. Los barrios paulistanos tienen dimensiones y poblaciones variables, bajo las diferencias de sus origenes históricos. La vitalidad de la dinámica urbana permite que la población participe en la organicidad del barrio, elegiendo sus puntos de encuentro y sus marcos referenciales, a veces pobres, pero ni por eso menos significativos para la vida cotidiana". ${ }^{8}$
\end{abstract}

\title{
1.2.- Una mirada geográfica sobre el barrio en el presente
}

En la Geografia, el barrio ha sido siempre considerado como la escala intermediaria entre la escala de la calle y la escala de la ciudad, necesaria al existir de la urbe. Desde la década de 1960, Tricart ya definia tres escalas principales del paisaje urbano:

- La escala de la calle, que corresponde al espacio abarcado por un observador en un punto cualquiera de la ciudad.

- La escala de barrio -formada por un conjunto de cuadras, de edificios, calles y plazas.

- La escala de la ciudad entera -considerada como un conjunto de barrios.

Estas escalas van a ser reconsideradas posteriormente por José Garcia Lamas:

- $\quad$ "Dimensión Setorial - la escala de la calle, la más pequeña unidad, o porción de espacio urbano con forma propia.

- Dimensión Urbana - la escala del barrio; es a partir de esta dimensión, o escala, que existe verdaderamente el area urbana, la ciudad o parte de ella. Presupone una estructura de calles, plazas o formas de escalas inferiores.

- Dimensión Territorial - la escala de la ciudad; en esta dimensión la forma se estructura a través de la articulación de diferentes barrios conectados entre sí, y con el soporte geográfico". ${ }^{9}$

- El barrio ideal en números - tamaño y población

Varios son los criterios para el dimensionamiento físico y poblacional ideal de un barrio. En el ejemplo de Carlos Nelson dos Santos, según el principio regular de las cuadrículas, estas serían módulos de dimensiones prefijadas y jerarquizadas, que podrían ser implantados sobre cualquier base físicogeográfica, y podrían expandirse en cualquer direción. En ese raciocinio la unidad mínima sería la parcela, de dimensiones prefijadas que, al agruparse de 20 a 48 parcelas, daría lugar a una cuadra. Agrupándose 9 cuadras daría lugar al vecindario, y 36 cuadras al barrio (este equivalente a 4 vecindarios, ya con una jerarquía de calles). En el vecindario, 8 cuadras serían residenciales, y 1 sería destinada a la implantación de plaza, escuela, guardería, centro de salud, y otros. Sería esa la estructura propuesta para el tejido urbano de ciudades nuevas, constituyendo el barrio la unidad más grande, anterior a la escala de la ciudad". ${ }^{10}$

Todavía siguiendo ese criterio dimensional, el Geógrafo José Donizete Cazollato, en su tesis de Master, hizo las diversas lecturas de la escala del barrio, llegando a las medidas de un barrio ideal:

"El barrio ideal tendría una extensión entre $0,40 \mathrm{~km}^{2}$ y $1,5 \mathrm{~km}^{2}$, y una población con alrededor de 8.000 habitantes; se tendría en cuenta elementos del paisaje de facil percepción, como vías, cursos de agua, líneas de transmisión, ferrovía, línea de relieve acentuado, etc., conservando la integridad de la via". ${ }^{11}$

\footnotetext{
8 WILHEIM, 1982, p. 63-65.

9 LAMAS, 1993, p. 73-76.

10 SANTOS, 1988, p. 123.

11 CAZOLLATO, 2005, p. 3, 115, 130, 13.
} 
REVISTA DE

URBANISMO

ISSN 0717-5051

http://revistas.uchile.cl/index.php/RU/index
Definiciones y espacialidades de barrio -arrabal, parroquia, districto y suburbio- y términos afines. Recife: los barrios centrales y del 'Conjunto Urbano de Casa Forte'

Definitions and spatialities - slum neighborhood, parish, district and suburb - and related terms. Recife: the central districts and the 'Conjunto Urbano de Casa Forte'

- Barrio como congruencia socio-espacial

La escala del barrio es la que más se acerca de un módulo social, o sea, un espacio con barreras, itinerarios y región, existindo una interrelación entre el estilo de vida y el comportamiento espacial.

"En general, parece que existen tres elementos esenciales a la definición de un barrio: características socioculturales (1), la situación de servicios y actividades (2), y la forma física y su simbolismo (3). Las características socioculturales afectan la importancia dada al área y el significado y los límites de este área dependen de ellas.

El barrio se define por su vez, cognitivamente y socialmente, como elemento de mediación entre el individuo y la ciudad, y, consecuentemente, es un esquema socioespacial, significativo para la población que percibe los límites. Estos límites, muchas veces calles, pueden ser claros o difusos. El esquema - edificios y gente - es más claro que el fondo informal de la ciudad. Todo mundo entiende el barrio como una parte de la ciudad que 'me pertenence'. El argumento de que el barrio ya no es importante hoy, puesto que las personas viven 'sin dominar un lugar', es contrario a la evidencia, aunque el barrio pierde valor como medio exclusivo de identificación". ${ }^{12}$

- Barrio como lugar urbano

Por fin, el barrio puede ser asociado aun al concepto de lugar urbano, una vez que sería la escala urbana más próxima a este, entendido como sentido de apropiación, afectividad, pertenencia.

"El lugar es la porción del espacio apropiable para la vida - apropiada a través del cuerpo - de los sentidos de los pasos de sus habitantes, es el barrio, es la plaza, es la calle, y en ese sentido podríamos afirmar que no sería jamás la metropolis o la ciudad 'lato sensu'. La metropolis no es 'lugar', ella solo puede ser vivida parcialmente, lo que nos remitiría a la discusión del barrio como espacio inmediato de la vida, de las relaciones cotidianas más finas - las relaciones de vecindad, el ir a las compras, o a caminar, el encuentro de los conocidos, el juego de pelota, el camino de una práctica vivida/reconocida en pequeños actos cotidianos y aparentemente sin sentido que crean lazos profundos de identidad, habitante-habitante, habitante-lugar". ${ }^{13}$

\section{2.-Denominaciones, definiciones y espacialidades: diccionarios técnicos, diccionarios de lenguas, entradas virtuales, enciclopedias, un 'popurri'.}

- La definición de barrio y términos afines en diccionarios y enciclopedias

'Arrabal', deriva del arabe arabadh, arrabad, ar-rabad (alrededores de una ciudad, suburbio), pero también significa:

- parte de la ciudad que está fuera de sus murallas o recinto;

- los extremos de una población, aunque estén dentro del recinto;

- alrededores de una población, proximidades, vecindario, cercanías, suburbios;

- población que esté cerca de una ciudad, dependiendo de ella;

- cercanías de una población, cosa conexa, anexa, llegada;

- parte de una ciudad ubicada en su periferia;

- barrio fuera de la puerta;

- barrio lejos del centro de la ciudad, conjunto de casas en las cercanías de una ciudad;

- Ex: Arrabal de Lapa: lugar de la parroquia de Santa Cristina, Concejo de Condeixa (Portugal)

- parte de una ciudad o población que esté fuera o en proximidad de sus límites. Lugar muy lejos del centro de una ciudad o población, alrededor, cercanía. Circunvecindario, en oposición al centro.

2 RAPOPORT, 1978, p. $155-163$.

13 CARLOS, 1996, p. 20-22, 74-75. 


\section{URBANISMO}

ISSN 0717-5051

http://revistas.uchile.cl/index.php/RU/index
Definiciones y espacialidades de barrio -arrabal, parroquia, districto y suburbio- y términos afines. Recife: los barrios centrales y del 'Conjunto Urbano de Casa Forte'

Definitions and spatialities - slum neighborhood, parish, district and suburb - and related terms. Recife: the central districts and the 'Conjunto Urbano de Casa Forte'

'Subúrbio', derivado del latin suburbium, sub + urb (que está cerca de la parte urbana, de la ciudad);

- arrabales, cercanías, aros, cercanías de ciudad, villa o cualquier población;

- vecindarios, alrededores;

- conjunto de aglomeraciones que están cerca de un centro urbano y participan de su existencia;

- región que sigue el arrabal, aunque fuera de la ciudad, pertenence a la jurisdición de ella;

- parte de la zona urbanizada de una ciudad ubicada en su periferia. En países pobres, el suburbio es habitado por baja renta. En los ricos, por alta renta, con equipamientos, obras y servicios de infraestructura;

- localidad ubicada en las cercanías de una ciudad y dependiente de esta;

- proximidad de ciudad, villa o otra población cualquier, arrabal, cercanía, alrededor. Barrio ubicado lejos del centro, en los arrabales de una ciudad, fuera o en las adyacencias de sus límites. Circunvecindad, en oposición al centro.

'Parroquia, del latin parochia (paroecia) - diócesis, parroquia, con influencia del párroco; y del griego paroikia (habitación vecina);

- jurisdición del párroco, iglesia matriz;

- distrito subordinado eclesiásticamente a un párroco; los habitantes de ese distrito;

- límite territorial sobre el cual se extiende la jurisdicción espiritual de un vicario;

- corporación elejida por los parroquianos para administrar los intereses de la iglesia;

- división territorial de una diócesis sobre la cual tiene jurisdición ordinaria un sacerdote, un párroco;

- comunidad cristiana dirigida por un párroco;

- población sobordinada eclesiásticamente a un párroco, conjunto de habitantes de ese territorio;

- localidad específica, ciudad, barrio.

'Feligresía', del latin filium ecclesiae (hijo de la iglesia, parroquiano); fregues + -ia;

- todos los feligreses de una parroquia;

- población desde el punto de vista eclesiástico;

- pequeña población, distrito de una parroquia;

- la menor división administrativa en Portugal, en las provincias y en las ciudades;

- circunscripción administrativa de una parroquia;

- clientela, grupo de compradores que utilizan los servicios de lo mismo médico, peluquero, abogado, etc.

'Distrito', del latim districtum, districtus (detenido, conectado, extensión de territorio dependiente de la misma jurisdicción);

-división territorial en la que se ejerce el gobierno o la jurisdición o inspección de cierta autoridad administrativa, judicial, fiscal, policial o sanitaria. Ej: Distrito Comercial, Districto Criminal, Districto Fiscal, etc.;

- división administrativa de algunas naciones, de un territorio;

- alzada, competencia;

- parte de la ciudad que, por determinación oficial, comprende para fines administrativos, uno o más barrios;

- pequeño pueblo o villa que crece al lado de alguna ciudad y es parte de ella, o bien, el terreno a su alrededor;

- grande división administrativa en Portugal y en otros países;

- En el Brasil, subdivisión del territorio municipal desprovista de autonomía. La sede del distrito llámase villa y es considerada área urbana del Município, con límites establecidos por ley municipal;

- cada una de las partes en que se divide el territorio del municipio.

'Barrio', del latin barra, barriu, barrium (lo que es separado, delimitado, cerrado); del árabe hispánico bar ri (exterior, suburbio) y del árabe clásico barri (salvaje);

- según Houaiss, viene de barra (travesa, divisoria), desde donde se habría formado el adjetivo barriu (que es lo que está del lado de fuera); el portugués bairro y el castellano barrio (arrabal, zona marginal de la ciudad, división de una ciudad), y todavía el catalán barri (valla, parque);

- cada una de las partes en que se acostumbra dividir una ciudad;

- porción de territorio en las cercanías de un núcleo urbano;

49 


\section{REVISTA DE}

URBANISMO

ISSN 0717-5051

http://revistas.uchile.cl/index.php/RU/index
Definiciones y espacialidades de barrio -arrabal, parroquia, districto y suburbio- y términos afines. Recife: los barrios centrales y del 'Conjunto Urbano de Casa Forte'

Definitions and spatialities - slum neighborhood, parish, district and suburb - and related terms. Recife: the central districts and the 'Conjunto Urbano de Casa Forte'

\begin{abstract}
- cada una de las divisiones administrativas de los Concejos de Lisboa y Porto, presidida por un administrador de barrio;

- división para la más precisa orientación de las personas y fácil control administrativo;

- parte de la ciudad que comprendía determinada área, ocupada por pueblos de la misma clase;

- arrayal o pequeño pueblo (Minas Gerais), con un pequeño comercio;

- para Celson Ferrari, el barrio no es necesariamente una unidad administrativa. Es una unidad espontánea, integrada por individuos y grupos primarios que pueden mantener entre sí contactos simpáticos, desinteresados, con conciencia de pertenencia a la misma comunidad;

- en Portugal, lugar de la parroquia de ...., el Concejo de .... (un barrio podría comprender una o más parroquias). Ej: Barrio de Bajo, con las parroquias de: Alvarenga, Concejo de Lousada; Dos Iglesias, Concejo de Paredes; San Juan de Fontoura, Concejo de Resende.
\end{abstract}

\title{
- La definición de barrio y términos afines en otras lenquas
}

En la lengua española, barrio deriva de la etimología:

"barr, bar, tierra, campo, campo inmediato a una población. Bar, barr, barrio, siguió llamándose ese campo mismo después de haberse edificado en él, y, por último, vino a significar barrio una de las divisiones locales o municipales de las poblaciones, y sobre todo de las poblaciones grandes. En algunas partes se entiende por barrio lo mismo que arrabal, grupo de población ubicado en el extremo de la misma, o un poco separado de ella". 14

'Arrabal' y 'suburbio' corresponden a cercanías, alrededores, barrio cerca a la ciudad o dentro de su jurisdicción, y suburbio, es citado aun como barrio de baja renta. La palabra arrabal corresponde al español arrabal, pueblo ubicado fuera de la muralla de la ciudad de entonces, pero junto a ella, o incluso dentro de la muralla, también adherido a su muro, un poco lejos de la malla urbana de la urbe antigua. "... cuando aumentaba el vecindario se formaban los 'arrabales'- 'arbad', en singular 'rabad', asimismo amurallados y con su propia mezquita, zocos, tiendas y demás edificios comerciales". ${ }^{15}$

'Parroquia' y 'Feligresía' corresponden al territorio que está bajo jurisdicción de un párroco, conjunto de parroquianos de una parroquia. Y aparece todavía como división administrativa dentro del municipio, en el caso del norte de España.

'Distrito' corresponde a la división territorial administrativa o judicial. Ej: distrito universitario, distrito judicial.

En Buenos Aires, los barrios son agrupados formando comunas. Esas comunas son areas que guardan características comunes, como por ejemplo, en muchas se tienen en comum las origenes de ses habitantes, más allá del patrimonio intangible de fiestas y tradiciones de indumentaria, culinaria y religión.

141941 apud SOUZA, 1989, p. 153.

15 VERA, 1990, p. 26. 


\section{REVISTA DE}

\section{URBANISMO}

\section{ISSN 0717-5051}

http://revistas.uchile.cl/index.php/RU/index
Definiciones y espacialidades de barrio -arrabal, parroquia, districto y suburbio- y términos afines. Recife: los barrios centrales y del 'Conjunto Urbano de Casa Forte'

Definitions and spatialities - slum neighborhood, parish, district and suburb - and related terms. Recife: the central districts and the 'Conjunto Urbano de Casa Forte'

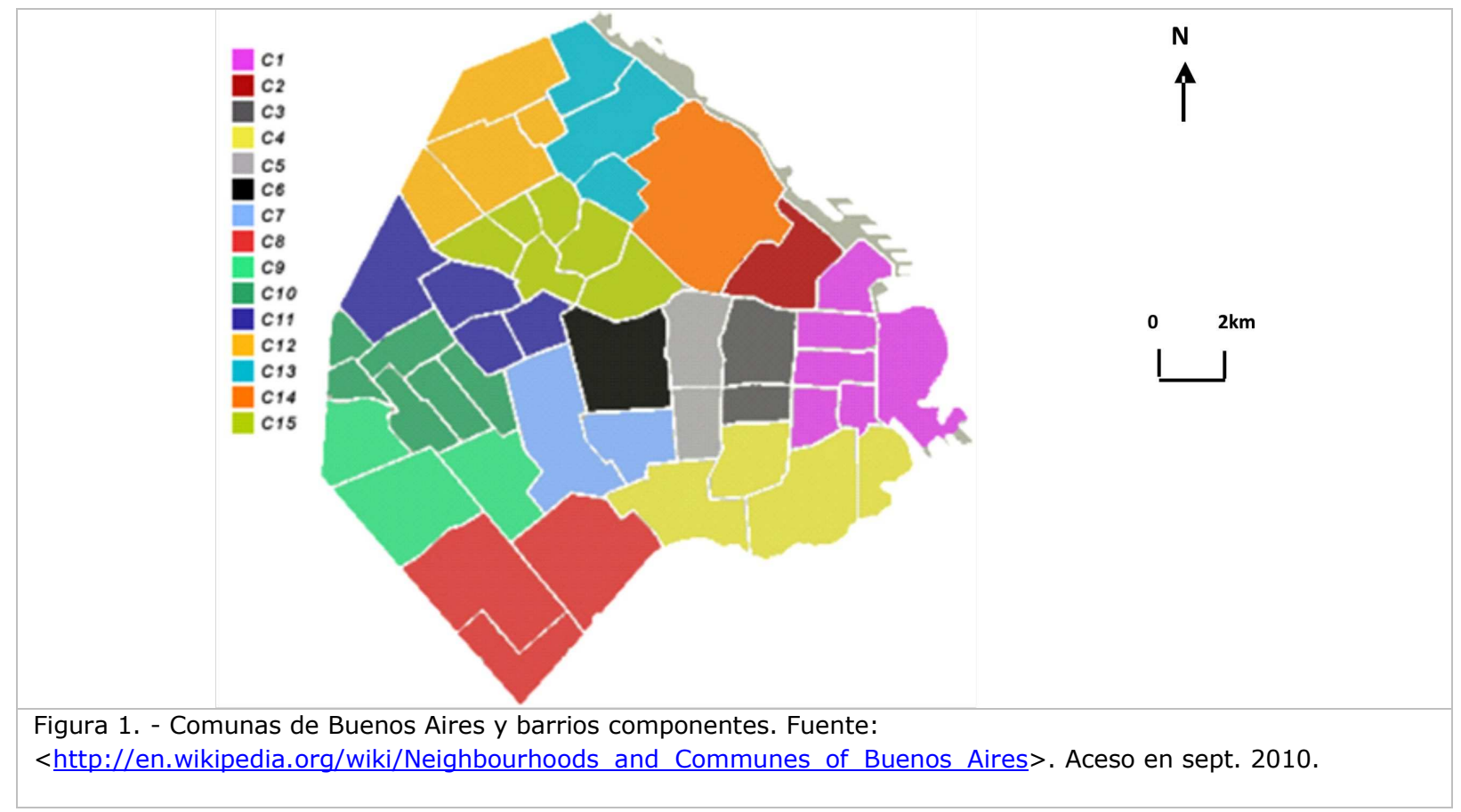

Similar al español, en italiano 'arrabal' y 'suburbio' asumen la misma nomenclatura - sobborgo, periferia; así como son sinónimos 'parroquia 'y 'feligresía' - parròcchia.

'Barrio' es asociado a rione (más común) y aun a 'quartiere di uma cittá' (parte de una ciudad), y 'distrito' es citado como división de una jurisdición, como distrétto.

En francés, encontramos los terminos 'arrabal' y 'suburbio' como sinónimos, correspondientes a los términos faubourg (barrio desarrollado en el exterior, más allá del territorio de una ciudad), banlieue (periferia), y todavía el environ.

'Feligresía' y 'parroquia' corresponden a paroisse (territorio que se extiende a jurisdicción espiritual de un cura.

'Barrio' corresponde a quartier de ville (parte de una aglomeración caracterizada por partes distintas que confieren una cierta unidad y una cierta individualidad, o delimitado por un perímetro con una discontinuidad espacial ... es un sector/división esencialmente social, con una cierta unidad económica y demográfica, una realidad histórica, un sentimiento de pertenencia). 'Distrito' corresponde a district, compétence (idea de jurisdición), arrondissement.

El francés fue la única lengua en que se encontró un diccionario francés-francés de términos urbanísticos exclusivamente, que ilustra, por ejemplo, el caso de París. En París, los quartiers son las divisiones que más se acercan del nuestro conocido barrio, los cuales unidos en número de 4 , forman 


\section{REVISTA DE}

\section{URBANISMO}

ISSN 0717-5051

http://revistas.uchile.cl/index.php/RU/index
Definiciones y espacialidades de barrio -arrabal, parroquia, districto y suburbio- y términos afines. Recife: los barrios centrales y del 'Conjunto Urbano de Casa Forte'

Definitions and spatialities - slum neighborhood, parish, district and suburb - and related terms. Recife: the central districts and the 'Conjunto Urbano de Casa Forte'

un arrondissement. Como se cada arrondissement estuviese dividido en 4 cuadrantes, haciendo un total de 20 arrondissements y 80 quartiers $^{16}$.

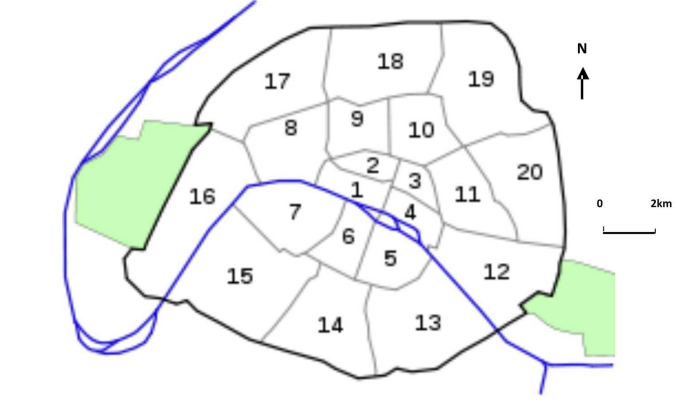

Figura 2.- Arrondissements de París actual. Están distribuídos según una espiral que se desarrolla en el sentido de los punteros del reloj a partir del punto central de la ciudad, localizado en el Louvre $\left(1^{\text {er }}\right.$ arrondissement).

Fuente:

http://pt. wikipedia.org/wiki/Arrondissements de Paris. Acceso en: sept. 2010.

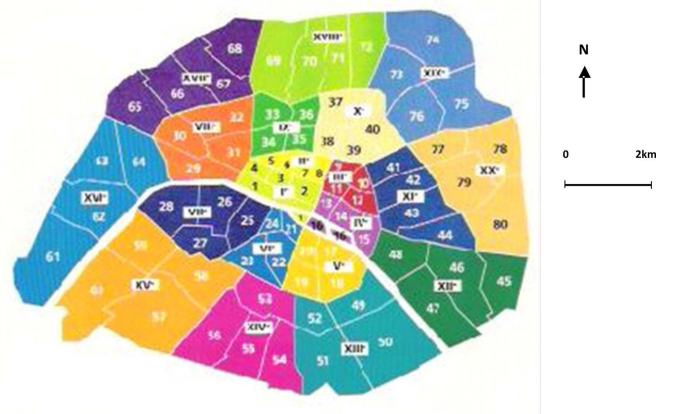

Figura 3.- Quartiers de Paris. Cada arrondissement está dividido en cuatro quartiers o barrios, que corresponden aproximadamente a los cuartos noroeste, noreste, sudoeste y sureste del respectivo arrondissement. Fuente: http://www.paris-walking-

tours.com/images/quartier.jpg Acceso en: sept. 2010

En inglés, 'arrabal' y 'suburbio' corresponden a suburbs, environs y outskirts, como siendo aquello que estuviese en el margen del tejido urbano, periferia, borde, límite. 'Parroquia'y 'feligresía' corresponden a parish, customers, conjunto de feligreses de aquella parroquia. 'Barrio'está relacionado a los términos quarter, ward (en el sentido de división administrativa) y al término neighbourhood (sentido de vecindario, relación de proximidad, comunidad sociable), dependiendo del sentido. 'Distrito' está relacionado a district, borough (división administrativa, circunscripción, sector).

"La palabra inglesa neighbourhood parece frecuentemente cubrir una escala intermedia entre la unité de voisinage y el quartier de la literatura sociológica culturalista francesa. Esto explica el porqué de enfatizarse el papel del neighbourhood como un 'área de relaciones primarias y espontáneas', lo que no combina con el concepto francés de quartier, aproximándose, eso sí, a la unité de voisinage. Todavía me parece que la neighbourhood unit de los anglosajones y la unité de voisinage, no son rigurosamente idénticas en materia de analogía vocabularia, muchas veces no aluden a la misma escala espacial, pues la unité me parece elástica al punto de abarcar escalas muy puntuales (como un edificio de apartamentos), lol

16 "Paris fue dividida por la primera vez en 12 arrondissements en 1795, siendo 9 en la margen derecha del Sena y 3 en la margen izquierda. Cada arrondissement está subdividido administrativamente en cuatro barrios (quartiers, cuartos), que corresponden aproximadamente a los cuartos noroeste, noreste, sudoeste y sureste del respectivo arrondissement. Estos 20 arrondissements están distribuídos según una espiral que se desarrolla en el sentido de los punteros del reloj a partir de un punto central de la ciudad localizado en el Louvre (10 arromdissement). Es así que los números más bajos corresponden a arrondissements más centrales y números más grandes a arrondissements más distantes del centro. Cada arrondissement es gestionado por un consejo de arrondissement con operación similar al consejo municipal, pero con poderes más limitados". (Artículo 'Arrondissements de Paris'. Fuente: Wikipedia. http://pt.wikipedia.org/wiki/Arrondissements de Paris>. Acceso en: sept. 2010. 


\section{REVISTA DE}

\section{URBANISMO}

ISSN 0717-5051

http://revistas.uchile.cl/index.php/RU/index
Definiciones y espacialidades de barrio -arrabal, parroquia, districto y suburbio- y términos afines. Recife: los barrios centrales y del 'Conjunto Urbano de Casa Forte'

Definitions and spatialities - slum neighborhood, parish, district and suburb - and related terms. Recife: the central districts and the 'Conjunto Urbano de Casa Forte'

que no sería el caso del neighbourhood. Sea como fuere, son las relaciones de tipo primario, y no las de tipo secundario como en el quartier, que definen en principio el neighbourhood. El district, otro referencial, se define por las relaciones de tipo secundario que se dan en su escala". ${ }^{17}$

Y, por último, citamos Portugal, citando como ejemplo la ciudad de Lisboa, dividida en cuatro grandes barrios y 54 parroquias, que serían equivalentes a las Regiones Político-Administrativas y barrios de Recife de hoy. En Lisboa, cada feligresía o parroquia, es devota a un santo o santa de la iglesia católica, con una división y límites que persisten aun hoy. Así, el $1^{0}$ barrio, correspondiente a la parte central y de tejido más antiguo, contiene el número mayor de parroquias.

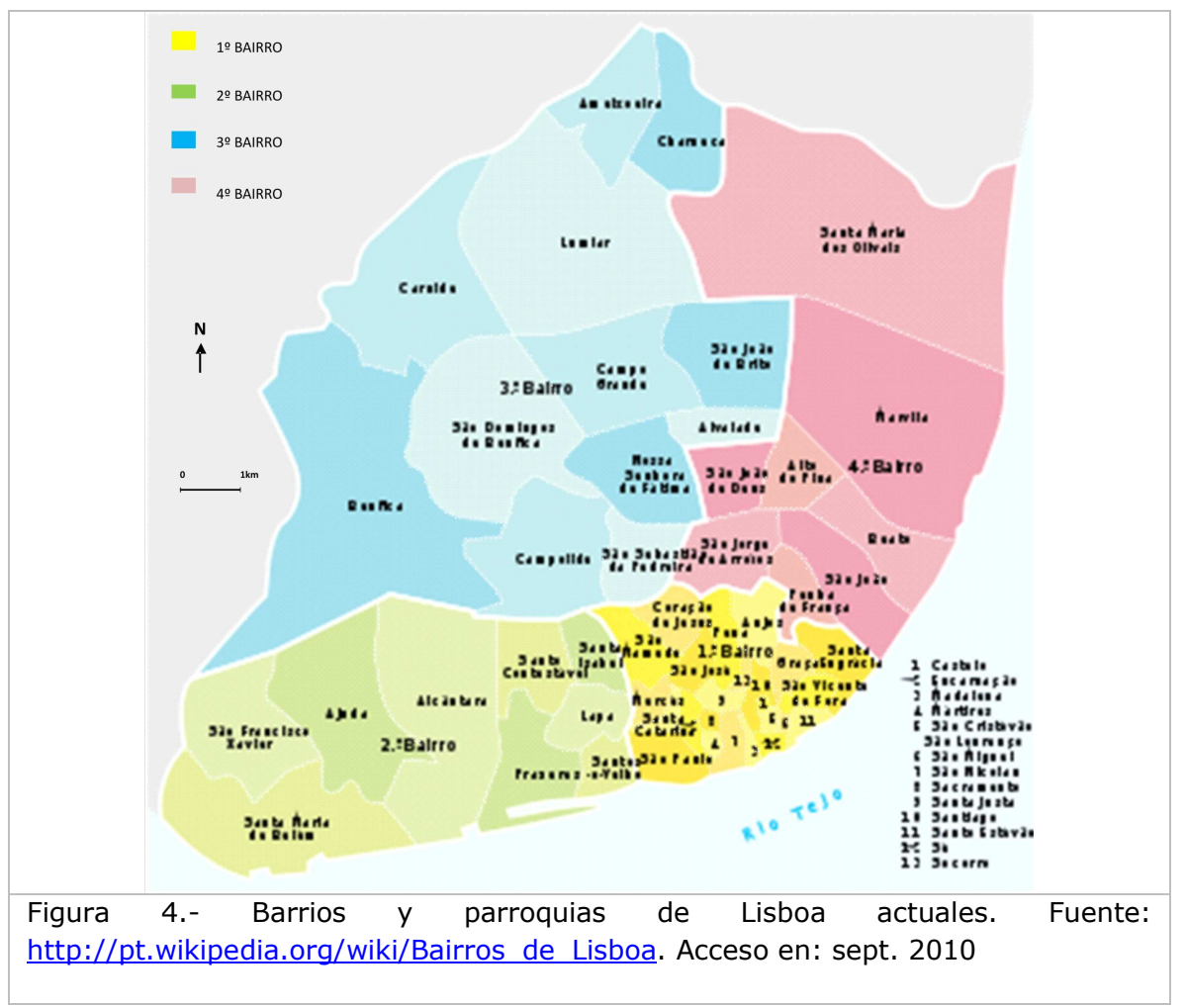

Para completar las ilustraciones, la ciudad de Recife, dividida en seis áreas más grandes - las Regiones Político-Administrativas (RPA's), y estas en barrios, con un total de 94 barrios.

17 Souza, 1989, p. 153-154, Grifos mios. 


\section{REVISTA DE}

\section{URBANISMO}

ISSN 0717-5051

http://revistas.uchile.cl/index.php/RU/index
Definiciones y espacialidades de barrio -arrabal, parroquia, districto y suburbio- y términos afines. Recife: los barrios centrales y del 'Conjunto Urbano de Casa Forte'

Definitions and spatialities - slum neighborhood, parish, district and suburb - and related terms. Recife: the central districts and the 'Conjunto Urbano de Casa Forte'

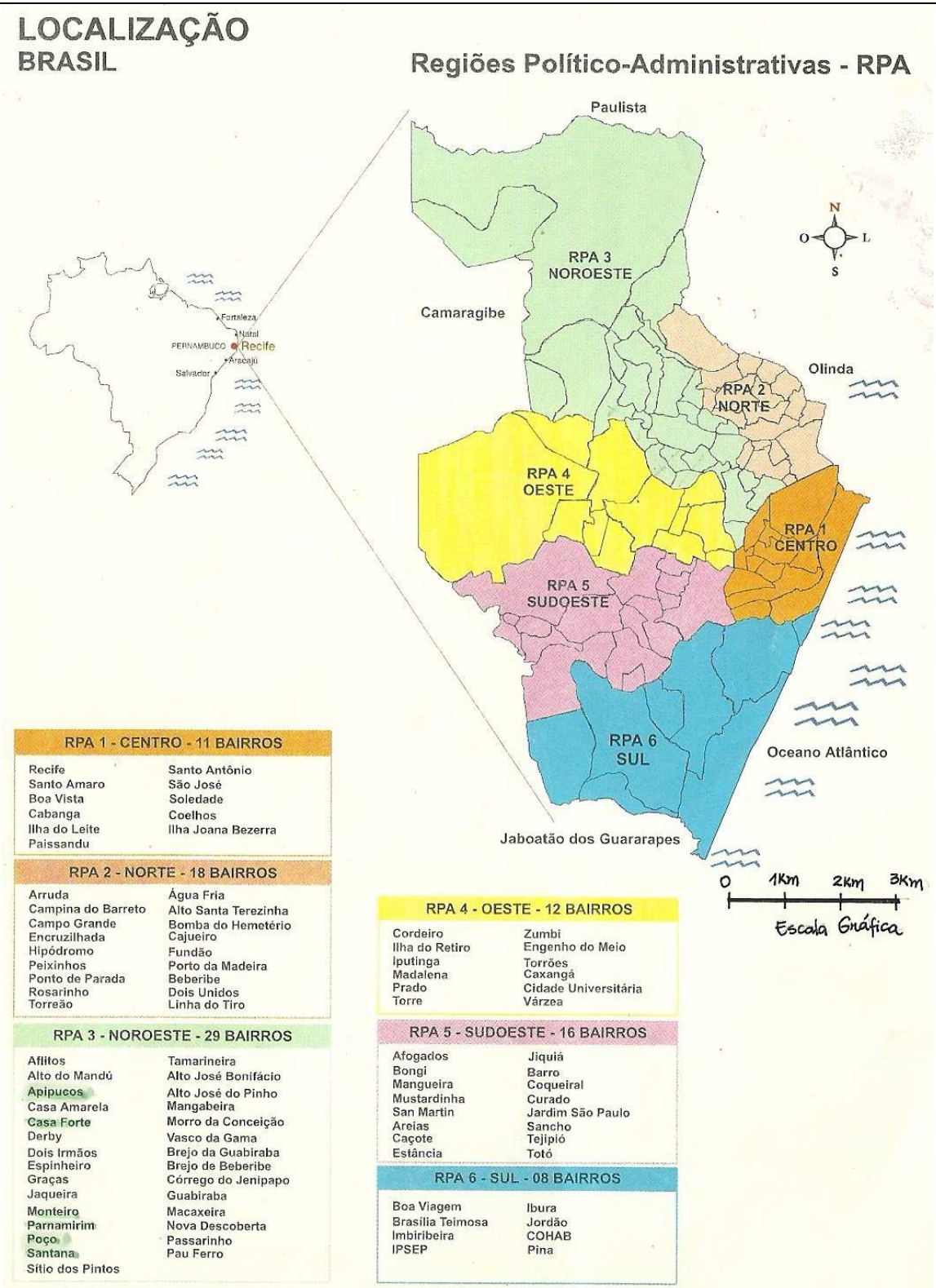

Figura 5.- Regiones Político-Administrativas del Municipio de Recife y barrios componentes. Fuente: RECIFE, Ayuntamiento de la Ciudad. El Recife en números. Recife: Secretaría de Planeamiento, Urbanismo y Medio Ambiente, 1998 (folleto). 
REVISTA DE

URBANISMO

ISSN 0717-5051

http://revistas.uchile.cl/index.php/RU/index
Definiciones y espacialidades de barrio -arrabal, parroquia, districto y suburbio- y términos afines. Recife: los barrios centrales y del 'Conjunto Urbano de Casa Forte'

Definitions and spatialities - slum neighborhood, parish, district and suburb - and related terms. Recife: the central districts and the 'Conjunto Urbano de Casa Forte'

\section{3.- Lo que define un barrio?}

\section{1.- ¿Una nomenclatura?}

Así como los nombres de los lugares tienen su significado, los nombres de clasificación también tienen Ios suyos: arrabales, alrededores, suburbios. La ciudad de Recife hasta mediados del siglo XIX (hasta llegar la ferrovía y la modernización de los medios de transporte) se concentraba en los barrios centrales y sus cercanías (Recife, Santo Antonio, San Jose, Boa Vista y parte de Santo Amaro, Coelhos, Ilha do Leite, principalmente). Los pueblos que estuviesen fuera de esa malla concentrada eran tenidos como arrabales, alrededores, suburbios. El origen de los nombres de los barrios recifenses -principalmente de los barrios históricos-, dicen mucho de sus personalidades, o de las personalidades de quién los habita.

El origen de los nombres de los barrios de Apipucos y de Parnamirim, vienen del tupi. Apipucos viene de apé-puc, que significaba 'cruce de caminos', "aunque algunos prefieren traducir el término como 'camino que se bifurca'. Es justamente en esa antigua bifurcación o cruce, que está ubicada la plaza principal del barrio. Esos caminos tenían el seguiente itinerario: uno hacia abajo para el Río Capibaribe y el otro venía de la Mata de Dos Hermanos". ${ }^{18}$ El barrio de Parnamirim tiene su nombre originado en dos terminos tupis que, juntos, significan 'riacho', o sea, río pequeño, paraná mirim.

El nombre del barrio de Santana es proveniente de la antigua iglesita de Santa Ana. Hoy es justamente en la calle Santana que está ubicada la Unión Brasilera de Escritores, sede Pernambuco. Localidad también conocida como 'Paço del Fidalgo', porque allí existía un paço (almacén de azúcar), de un noble portugués ${ }^{19}$.

El nombre del barrio de Monteiro ha venido del apellido del último propietario del ingenio del mismo nombre, Francisco Monteiro Bezerra. Localidad donde los veranos en el Capibaribe fueron famosos, y muy aristocráticos. Así como otros arrabales ribereños, vivió su apogeo en el siglo XIX.

El barrio de Casa Forte tiene origen también conectado al ingenio de mismo nombre, reforzado por el hecho de haber sido la casa grande del ingenio una auténtica 'casa fuerte' para los holandeses, cuando perdieron la batalla en el Monte de las Tabocas en 1645. La heredera de la propiedad, que fuera casada con capitanes del ejército enemigo, fue protagonista de muchas historias y rumores.

Y el nombre del Poço da Panela viene de la principal actividad que va a desarrollarse en estas tierras. En mediados del siglo XVIII, época de los baños terapéuticos en el río Capibaribe, un rico comerciante cuya esposa padecía de una enfermidad grave, hizo la promesa de donar parte de su propriedad para construcción de una capilla como agradecimiento por la curación. Y así pasó. Obteniendo la curación, en 1770, fue ubicada la pequeña Iglesia de Nuestra Señora de la Salud. Al lado de esta, "en la margen izquierda, en la curva de la misma vía, cuyas tierras forman una suave pendiente hacia el río, descubrieron una abundante componente. Hicieron, entonces en aquel lugar, una excavación para formarse un pozo regular, y en su fondo pusieron una gran olla de barro y pasaron a llamarla como Poço da Panela, lo que se tornó extensivo a la localidad así todavía mantenida" 20.

\footnotetext{
CAVALCANTI, 2002, p. 202.

Ibid, p. 125.

20 Ibid, p. 158.
} 
REVISTA DE

URBANISMO

ISSN 0717-5051

http://revistas.uchile.cl/index.php/RU/index
Definiciones y espacialidades de barrio -arrabal, parroquia, districto y suburbio- y términos afines. Recife: los barrios centrales y del 'Conjunto Urbano de Casa Forte'

Definitions and spatialities - slum neighborhood, parish, district and suburb - and related terms. Recife: the central districts and the 'Conjunto Urbano de Casa Forte'

Los barrios del centro tienen origen en el plan urbanístico holandés, datado de mediados del siglo XVII, los cuales, incluso después de la retomada por los portugueses y por los de la tierra, van mantener sus trazos (no su volumetría...). Años después serán nombres de parroquias de Recife.

\section{2.- ¿Un límite físico-espacial?}

Como recorte físico-espacial, el barrio es delimitado, un área que es circunscrita por ley, aunque se definen límites que no siempre son reconocidos por la población. Muchas veces las nociones de centralidad lo definen más fuertemente que sus límites. Un edificio, un parque, una iglesia y su largo, un área abierta al río, la densidad de la vegetación, son a veces, elementos más definidores.

En las ciudades antiguas, sus límites eran más claramente definidos: una muralla, una empalizada, unas puertas, un cinturón de ríos o de bosques que los rodeaban. Era más claro el sentimiento de pertenencer o de no pertenencer. Hoy, los límites ya no son tan visibles, ni comúmente reconocidos y aceptados por todos.

Vamos en la dirección a una contemporaneidad sin límites, sin fronteras, de rapidez y conocimientos simultáneos en cualquier parte, lo global y lo local suceden al mismo tiempo, sin exclusividad. En ese sentido, en la esfera del barrio, ¿sus límites todavía tienen sentido? Tal vez sí, pues todavía es esa la escala que más se acerca a la de los lugares urbanos, a la escala del afecto, a la escala del vecindario al cual se pertenece, aun con líneas abstractas y sobrepuestas.

\section{3.- ¿Sus espacios libres?}

En las ciudades de otrora, teníase muy bien definidos los llenos y los vacíos. Las parcelas eran construidas casi en su totalidad, los espacios sobrantes eran destinados a las vías. Los que no fuesen vías, generalmente eran patios de iglesias, o plazas, o borde de la dársena, márgenes de ríos o mar. Los barrios históricos tenían en los áreas contiguas a las iglesias sus espacios libres predominantes. En Recife, dada a la situación geográfica, los patios a veces se abrían al río, o a la iglesia y río al mismo tiempo, sugiriendo 'ventanas', marcando el trazado y definiendo identidades. Iglesias y patios muchas veces no estaban ubicados obrigatoriamente en el centro geométrico-espacial del territorio demarcado, pero por eso no dejaban de ser su símbolo de reconocimiento.

La presencia masiva de plazas y ventanas orientadas al río en los barrios de la tierra baja del Capibaribe, contrastan con la cantidad de iglesias y patios en el centro, patios que se abrían o todavía aun se abren hacia el agua. Ayudan a denominar esos tejidos, a definir el carácter de estos barrios. Los del centro como parroquias, los de la tierra baja como arrabales, suburbios. Espacios libres que pueden ser observados en las ilustraciones siguientes, barrio a barrio estudiado.

\section{4.- ¿El curso del río, su tierra baja o 'ventanas' que se abren para él?}

El soporte físico-geográfico fue el condicionante más grande de toda la ocupación inicial de la costa brasileña y a veces también de la expansión interior. Los núcleos primeros que se tornarán ciudades van estar cerca a los márgenes de aguas o hasta en áreas tomados por vertederos al mar y al río, como es el caso del Recife. Los barrios, y principalmente, los barrios históricos, van a hacer parte de este planeamiento inicial de la ocupación.

En Recife no fue diferente. Las características físico-geográficas del sitio condicionaron sus usos y formas de ocupación, su subdivisión. Lo natural desde siempre indujo y favoreció lo artificial en esta ciudad.

56 
REVISTA DE

URBANISMO

ISSN 0717-5051

http://revistas.uchile.cl/index.php/RU/index
Definiciones y espacialidades de barrio -arrabal, parroquia, districto y suburbio- y términos afines. Recife: los barrios centrales y del 'Conjunto Urbano de Casa Forte'

Definitions and spatialities - slum neighborhood, parish, district and suburb - and related terms. Recife: the central districts and the 'Conjunto Urbano de Casa Forte'

El terreno donde ha nacido Recife corresponde exactamente al delta formado por los ríos Capibaribe, Beberibe, Tejipió y Jiquiá, que suministran la planicie y desembocan cerca a ese punto. Estos mismos ríos fueron los vectores que impulsaron el crecimiento hacia el interior de la planicie, a lo largo de sus márgenes, extendiéndose hasta el cinturón de colinas circundantes. Ese fue por mucho tiempo el límite espacial del Recife y de sus barrios.

Y en cuanto a las ventanas hacia el río, estas se dieron a través de los patios de iglesias que se estiraban hasta sus márgenes, algunas plazas en el centro aun funcionan como ventanas, aunque algunas como caminos, aceras más retrasadas en la orilla del río, en varios puntos. Espacios que de hecho ayudaron a configurar la identidad de esos barrios, junto al agua, pero que por si solos no son definidores. Las iglesias y sus patios son mucho más fuertes en el corazón de esos barrios. Cuando sus patios llegan hacia el agua, ese rebatimiento gana más fuerza.

\section{5.- ¿Una forma, un contenido y una escala urbana?}

Un barrio corresponde a un área, y como área es definida por un perímetro, un tamaño y una forma. Una forma que trae en su interior un contenido. Un casco urbano, depositario de los diversos tiempos de la ciudad. De los valores naturales, valores constructivos, valores históricos, valores sentimentales. Nombres. Nombres de personajes y nombres de calles, de plazas, de iglesias.

La división de las primeras cuadras se da a través de un grupo de casas y callejones al estilo portugués, o a través del sistema de canales y fosos de los holandeses. Avanzando para el interior, se formaron los ingenios, 'ganglios' a lo largo de los márgenes de estos ríos, cuyas aguas servían para el cultivo y como medio de flujo de la producción. Ubicación y equipamientos generarán la síntese espacial de los futuros barrios que desde allí se originarán.

Las capillas seguirán siendo las referencias espaciales de esos barrios, generalmente cerca de las casas grandes, cuyos espacios fronterizos seguirán siendo zonas áridas, hoy plazas, como en Monteiro, Casa Forte y Apipucos.

En el centro, después de la retomada portuguesa, canales y zanjas fueron eliminados, y sucesivos rellenos fueron hechos, de un lado y del otro de la isla de Antonio Vaz. Entonces vinieron las instalaciones de los órdenes religiosos: carmelitas, franciscanos, jesuítas. Con poderes de negociar, junto a la administración de la provincia, la forma y tamaño de sus patios, quiera que fuesen en la línea de la costa o en el interior de la red de calles, creando en el incipiente casco urbano, espacios libres que van a continuar hasta hoy, característicos de esa parte de la ciudad, agregando fuerza espacial a esta trama.

\section{4.-La Ciudad de Recife: los barrios centrales y los barrios del Conjunto Urbano de Casa Forte}

\section{1.- Los límites naturales}

La descripción del sitio donde se ubicará la ciudad de Recife es tenida siempre como facilitadora, invitativa, desde el punto de vista físico-geográfico, por su condición de fluvio-marina, Ilanura alimentada por varios ríos como venas, convergiendo a un arrecife natural, un área de aguas represadas naturalmente, y rodeada de cerros al fondo, como que cerrando y protegiendo ese ambiente. Y es justamente en la costa, en el delta de islas que había en su canal, en la conjunción, en la desembocadura de los dos principales ríos (Capibaribe y Beberibe), que se va a situar el núcleo primitivo, ubicándose la lengüeta de tierra entre los arrecifes y el aceso a la parte alta de Olinda, escojida posteriormente para situar la base de la Capitanía. 


\section{REVISTA DE}

\section{URBANISMO}

ISSN 0717-5051

http://revistas.uchile.cl/index.php/RU/index
Definiciones y espacialidades de barrio -arrabal, parroquia, districto y suburbio- y términos afines. Recife: los barrios centrales y del 'Conjunto Urbano de Casa Forte'

Definitions and spatialities - slum neighborhood, parish, district and suburb - and related terms. Recife: the central districts and the 'Conjunto Urbano de Casa Forte'

De la condición de puerto natural a organismo artificial, Recife pasa a tener sucesivas luchas para establecerse. Primero los rellenos, tierras tomadas al mar y al río, en seguida los canales de drenaje de ese charco, después los puentes de conexión de una isla con otra, en la medida en que la población crecía y la urbe se expandía.

El panorama inicial del Recife daba cuenta del barro, frágiles humedales y pequeñísimo pueblo de pescadores y actividades conectadas al puerto natural, y Olinda más adelante, con todo el aparato jurídico-religioso de la capitanía, en la faja de la costa. En el interior de ese territorio, había fértiles tierras bajas que luego fueron convertidas en unidades productivas de azúcar, los ingenios.

Según el autor Viterbo, la palabra 'arracef' o 'arracife' procede del arabe común 'ar-racif', acera, camino pavimentado; línea de escollos y que significa todavía en algunos dialectos del norte de África 'pared que sirve de apoyo, presa, muralla, muelle, embarcadero. En el árabe clásico significaba el adjetivo 'firme', y en el castellano 'camino, banco o bajío de mar'21.

Aun en el siglo XVII, con la llegada de los primeros colonizadores, son fundadas tres villas, cuyas ubicaciones de asentamiento se dan en tres estuarios en la costa, siguiendo los preceptos portugueses de la época sobre la fundación de villas: áreas protegidas por colinas, facilmente defendibles, tierras fértiles y cerca, o en la orilla, del agua. Así nacen las villas de Santa Cruz, de Nuestra Señora de la Concepción, la Villa d'Olinda y los poblados de 'Recife de navíos' y de Nazare (hoy Cabo de Santo Agostinho). Villas compuestas por parroquias. La Villa de Olinda es escojida para ser la sede de la Capitanía, por contener algunas características espaciales, estar cerca de los negocios y las facilidades político-administrativas.

\footnotetext{
21 VITERBO, 1865 , p. 573 , v. I.
} 


\section{REVISTA DE}

\section{URBANISMO}

ISSN 0717-5051

http://revistas.uchile.cl/index.php/RU/index
Definiciones y espacialidades de barrio -arrabal, parroquia, districto y suburbio- y términos afines. Recife: los barrios centrales y del 'Conjunto Urbano de Casa Forte'

Definitions and spatialities - slum neighborhood, parish, district and suburb - and related terms. Recife: the central districts and the 'Conjunto Urbano de Casa Forte'

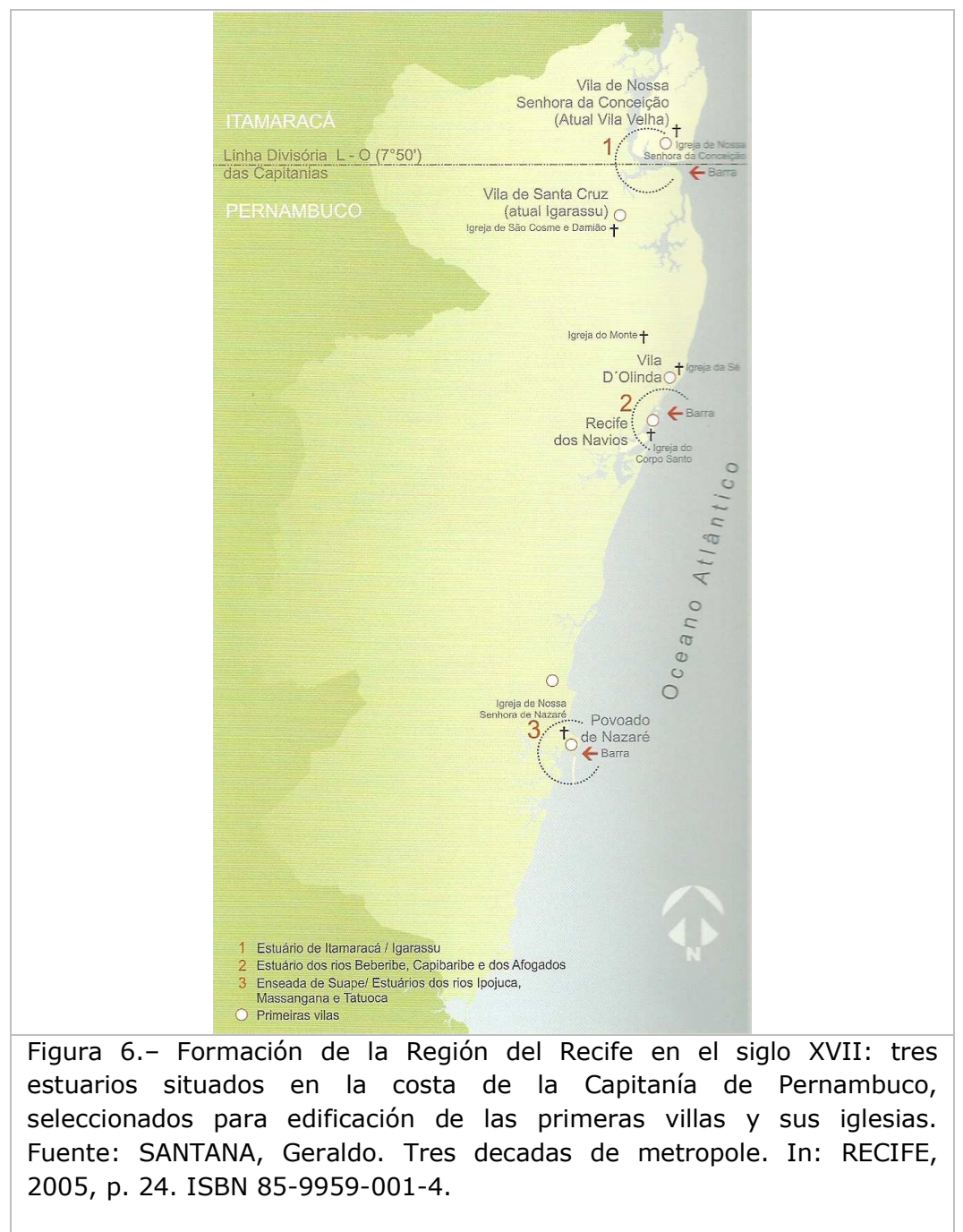

\section{2.- Su historia urbana de ocupación}

La historia de Recife empieza de hecho a partir de la invasión holandesa y consecuente implantación de su plan urbanístico y de negocios. La situación espacial del Recife se asocia a las características físicas de su territorio, y el oro blanco alcanza altos rendimientos en la bolsa internacional. No pasa mucho tiempo para que la gran empresa de la época - La Compañía de las Indias Ocidentalesinvertiese emprendimientos varios a esas tierras. Sin embargo, no consiguen imponerse en la sede de la capitanía, tampoco hacerse obedecer, y queman Olinda entonces, causando todavía mayor déficit de vivienda para la aldea de Recife, lo que se agrava por causa de la población que llegaba en las embarcaciones en forma creciente. En un primer momento ascienden en las casas de Recife alto, pero 
REVISTA DE

URBANISMO

ISSN 0717-5051

http://revistas.uchile.cl/index.php/RU/index
Definiciones y espacialidades de barrio -arrabal, parroquia, districto y suburbio- y términos afines. Recife: los barrios centrales y del 'Conjunto Urbano de Casa Forte'

Definitions and spatialities - slum neighborhood, parish, district and suburb - and related terms. Recife: the central districts and the 'Conjunto Urbano de Casa Forte'

eso no resuelve los problemas. Sigue entonces la expansión de la ciudad en otras zonas, asociadas al plan urbanístico trazado por los holandeses, previamente a la ocupación de la Isla de Antonio Vaz.

Mientras las ciudades Maurícia y Recife vivían sus días de gloria con construcciones y remodelaciones urbanas, en el interior de la planicie recifense prosperaban los ingenios. Según las memorias del capitán Duarte Coelho, en el año de la invasión holandesa (1630), había 16 molinos o ingenios de azúcar, cuya producción bajaba el rio en batéis, especie de barcazas, para ser almacenados y comercializados en el puerto de Recife. La ubicación de estos ingenios era condicionada a la proximidad del río, casi siempre el Capibaribe (a veces también el Beberibe), pues más allá del embarque también se necesitaba agua para la producción de caña-de-azúcar.

Los ingenios son: São João (1), Santo Antônio (2) y el del Meio (3), S. Francisco (4), S. Brás (5) y S. Sebastião (6) que tomó después el nombre de Curado, Torre (7) Marcos André, S. Paulo (8), Madalena (9), Mendonça, Apipucos (10), Monteiro (11), Santos Cosme e Damião (12), Casa Forte (13), entonces llamado Dona Ana Paz, Beberibe (14), Jiquiá (15) y Ambrósio Machado (16), que estaba ubicado entre el ingenio Madalena y el actual de Cordeiro ${ }^{22}$.

Los ingenios dejarán también, como legado, parte de sus equipamientos, la iglesia y la casa grande. Y cuando no dejaron la estructura física propiamente dicha, por lo menos dejaron señalada su ubicación. Así lo es en Apipucos, el lugar de la ubicación de su capilla y posiblemente parte de las instalaciones de los esclavos al lado de la capilla en la cima de la colina. En Monteiro no quedó nada en pie, se sabe solamente que la antigua ubicación de la casa grande, hoy corresponde a una escuela. En Casa Forte el lugar de la casa grande es hoy un colegio, y al lado está la iglesia, si no la misma, en la misma ubicación. En todos estos casos, los patios frontales al templo constituyen hoy una plaza, un espacio con vegetación.

\section{3.- La expansión urbana en dirección al interior de la planicie}

La ciudad necesitaba expandirse, ir más allá de los barrios de Santo Antonio y San Jose. Los intercambios comerciales, los navíos a vapor intercontinentales ya eran frecuentes. Existía una nueva forma de vivir y de disfrutar la ciudad. La burguesía ya afloraba en Recife, y frecuentaba los teatros, los cafes, las aceras públicas. La ciudad necesitaba modernizarse. Fue la época de los avances en los medios de transporte, y de los mejoramientos de los servicios públicos.

Con la llegada de las compañías de infraestructura urbana en Recife, vienen también sus principales empleados estranjeros, en gran parte ingleses y alemanes, que influenciados por las ideas de las ciudades jardines, van elegir los barrios de lo bajo del Capibaribe (Conjunto Urbano de Casa Forte) para vivir, ya que en pocos minutos estaban en el centro de la ciudad, a través de las ferrovías implantadas. En estos suburbios podían acercarse al verde, cultivar jardines, coleccionar flores, mariposas y otros insectos, practicar ciertos tipos de deportes al aire libre, nadar, pescar, enfin, vivir más tranquilamente y con un ritmo más lento, bajo un padrón y un ideario que va a perdurar hasta hoy en esos barrios. Aún con los contratiempos y con la agilidad y rapidez de los días de hoy, siglo XXI, es esa la imagen de Casa Forte en los recifenses.

22 CASTRO, 1957, p. 264.

60 
REVISTA DE

URBANISMO

ISSN 0717-5051

http://revistas.uchile.cl/index.php/RU/index
Definiciones y espacialidades de barrio -arrabal, parroquia, districto y suburbio- y términos afines. Recife: los barrios centrales y del 'Conjunto Urbano de Casa Forte'

Definitions and spatialities - slum neighborhood, parish, district and suburb - and related terms. Recife: the central districts and the 'Conjunto Urbano de Casa Forte'

\section{4.- Los primeros aglomerados/pueblos}

El binomio 'centro puerto/ingenios' va a predominar por un largo tiempo. De un lado el centro volcado a los servicios, a los intercambios, a la exportación de productos y hasta viviendas, en un espacio físico condensado y recortado por las curvas de las aguas de los ríos y del mar, y la inmensa planicie interior salpicada por ingenios y pueblos que funcionaban como 'ganglios' de ese incipiente casco urbano que empezaba a delinearse.

Tres cronistas del Recife describen, en sus tiempos, e ilustran los alrededores, los suburbios y los arrabales de Recife. Cronistas que presentan algunos pueblos en común, hoy todos barrios.

Francisco Pereira da Costa, autor de entre otras obras de los Anales Pernambucanos, un compendio de varios volúmenes que se parecía a una enciclopedia, describe los 'alrededores recifenses' ${ }^{23}$ como siendo: Afogados, Apipucos, Arraial, Barreta, Barro, Boa Viagem, Casa Forte, Chora Menino, Coelhos, Cordeiro, Curcuranas, Dois Irmãos, Estância, Jiquiá, Imbiribeira, Madalena, Manguinho, Monteiro, Poço da Panela, Ponte d'Uchoa, Remédios, Tejipió, Torre, Várzea.

Ya para Flávio Guerra ${ }^{24}$, los 'suburbios histórico', eran: Monteiro, Apipucos, Passagem da Madalena, Casa Forte, Jiquiá, Beberibe, Afogados, Poço da Panela, Torre, Campo Grande, Estrada dos Remédios, Dois Irmãos, Casa Amarela, Pina, Várzea, Ponte d'Uchoa y Tejipió. Mientras que las 'viejas iglesias'se ubicaban en gran parte en el centro, y algunas otras en esos suburbios históricos: Iglesia de Pilar, Igleja de Boa Vista, Iglesia del Livramento, Iglesia del Espírito Santo, Iglesia de las Fronteras, Iglesia de la Peña, Capilla de la Concepción (Jaqueira), Capilla de la Concepción (Juan de Barros), Iglesia del Buen Jesus de los Martirios, Iglesia de Santo Amaro, Iglesia de San Jose de Ribamar, Iglesia del Rosario, Iglesia de Santa Cruz, Iglesia de la Madre de Deus, Capilla del Morro da Conceição, Iglesia de Santa Cecília, Iglesia de Boa Viagem, Iglesia del Rosario de Santo Antonio, Iglesia de la Concepción de los Militares, Iglesia Matriz de Santo Antonio, Iglesia de San Jose del Manguinho, Iglesia del Carmo, Iglesia de San Pedro de los Clérigos, Iglesia del Rosário de Boa Vista, Iglesia de Santa Teresa, Iglesia de Santa Rita de Cassia, Iglesia del Convento de Santo Antonio, Iglesia de San Francisco de las Chagas, del Orden Tercera de San Francisco de Recife, Iglesia de Prazeres.

Y para F. H. Carls, en el 'Albúm de Pernambuco e seus arrabaldes: 1878' 25 , los arrabales de Pernambuco, ilustrados en sus célebres litografias, serían: Afogados, Soledade, Madalena, Estância, Ponte de Uchoa, Chacon, Jaqueira, Apipucos, Beberibe, Caxangá, Olinda, Santo Agostinho do Cabo, Escada, Paudalho.

Según el 'Diccionário Chorographico, Histórico e Estatístico de Pernambuco' 26 , de 1910, las parroquias de Recife eran 11: (1) Recife (S. Frei Pedro Gonçalves), (2) Santo Antonio, (3) San Jose, (4) Boa Vista, (5) Santo Amaro ou Santo Amaro das Salinas, (6) Graças, (7) Afogados, (8) Madalena, (9) Torre, (10) Poço da Panela y (11) Várzea.

4.5. Los barrios de Recife, en particular los barrios centrales y los barrios del Conjunto Urbano de Casa Forte hoy.

Jerárquicamente, las primeras parroquias, al pasar al control del Estado, dieron origen a las Zonas Administrativas. En los años 80s esas Zonas Administrativas ya se encontraban espacializadas en el

23 COSTA, F. A. Pereira, 2001, p. 5-6 (reedición).

24 GUERRA, 1960, p. 269, 270.

25 BRUSCKY, 2007, índice (reedición del álbum de F. H. Carls).

26 GALVÃO, 1910, p. 02-05, 28-31, 47-53, 59-62, 71-77, 169-171, 195-198, 289-293, 373-375, 392-396. 


\section{REVISTA DE}

\section{URBANISMO}

ISSN 0717-5051

http://revistas.uchile.cl/index.php/RU/index
Definiciones y espacialidades de barrio -arrabal, parroquia, districto y suburbio- y términos afines. Recife: los barrios centrales y del 'Conjunto Urbano de Casa Forte'

Definitions and spatialities - slum neighborhood, parish, district and suburb - and related terms. Recife: the central districts and the 'Conjunto Urbano de Casa Forte'

territorio recifense, presentando otro elemento administrativo - los Sectores Censales, que las dividen en porciones inferiores - los barrios o sectores, imponiendo límites que van a ser absorvidos e incorporados en la nueva división político-administrativa del municipio, al final de los años 90 (Decreto de Ley 16.213/97). Por este decreto el Municipio de Recife queda dividido en 94 barrios, agrupados en 6 Regiones Político-Administrativas (RPA's): RPA1 - Centro (11 barrios), RPA2 - Norte (18 barrios), RPA3 - Noroeste (29 barrios), RPA 4 - Oeste (12 barrios), RPA5 - Sudoeste (16 barrios) e RPA6 - Sul (08 barrios).

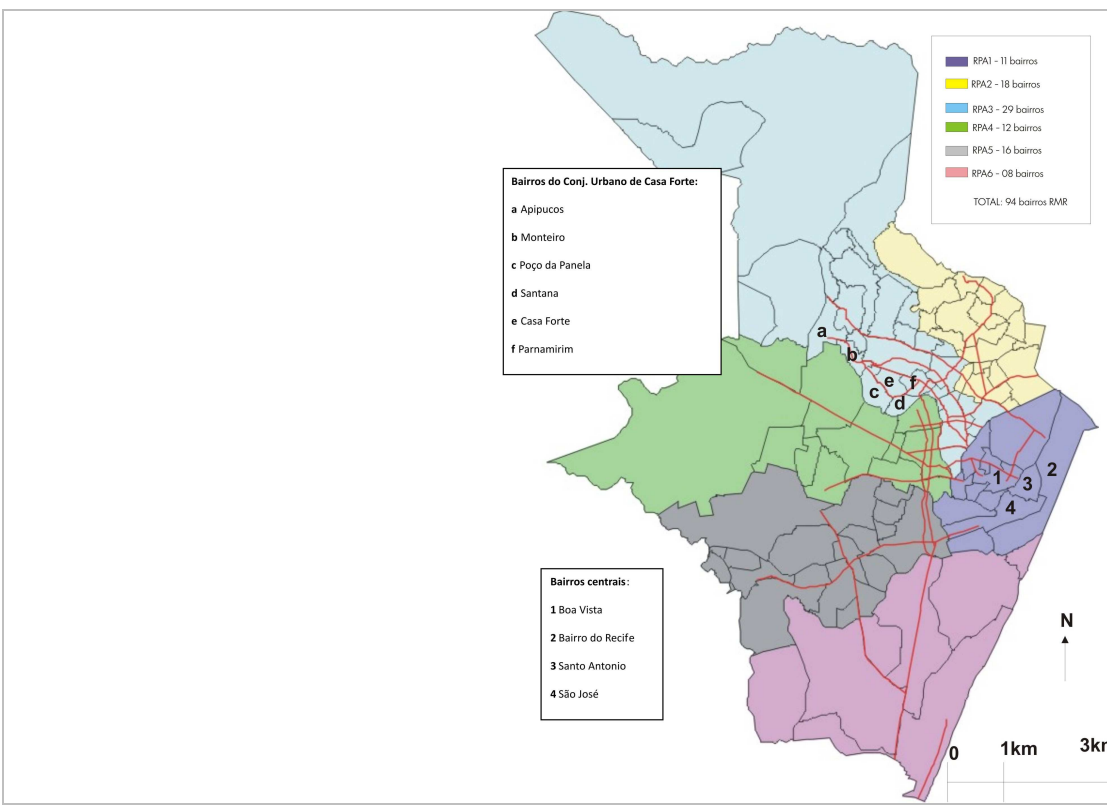

Figura 7.- Barrios en estudio y sus localizaciones en las RPA's correspondientes. Mapa de fondo: Regiones Político-Administrativas (RPA's) del Municipio de Recife, según la Ley 16.293, de 22/01/97. Disponible en: <http://www.recife.pe.gov.br/pr/secplanejamento/inforec/mapasRPA1.php>. Aceso en: nov. 2010.

El centro, a pesar de tener un aumento de edificios en altura y proyectos modernos, sigue emncontrando en los campanarios de las iglesias unas referencias espaciales. Las casas que otrora abrigaron una agitada vida de inmigrantes, están en muchos casos cerradas y deterioradas. Pero las huellas, la esencia de sus inmigrantes, su alma, aun impregnan sus materialidades, como es el caso de los judíos en la Boa Vista.

Los barrios de la tierra baja del Capibaribe tuvieron origen en aquellos primeros ingenios ubicados planicie adentro, que después fueron convertidos en sitios de vacaciones y luego en viviendas definitivas. La escala ya viene definida hace cuatro siglos en la división de esa urbe cuatrocentenaria.

Los barrios del Conjunto Urbano de Casa Forte tuvieron origen en los ingenios de azúcar estratégicamente ubicados en sus tierras, que a veces fueron desmembrados de otros: el ingenio Apipucos fue desmembrado de las tierras del ingenio Montero, así como el ingenio de Dois Irmãos fue desmembrado del de Apipucos, años después. La misma dinámica pasó a Poço da Panela, cuyas tierras

62 


\section{REVISTA DE}

\section{URBANISMO}

ISSN 0717-5051

http://revistas.uchile.cl/index.php/RU/index
Definiciones y espacialidades de barrio -arrabal, parroquia, districto y suburbio- y términos afines. Recife: los barrios centrales y del 'Conjunto Urbano de Casa Forte'

Definitions and spatialities - slum neighborhood, parish, district and suburb - and related terms. Recife: the central districts and the 'Conjunto Urbano de Casa Forte'

eran parte del ingenio Casa Forte, erigiéndose en 1817 una parroquia en la población de Poço da Panela, bajo invocación de N. S. de la Salud. Santana y Parnamirim también tenían parte de las líneas actuales pertenencientes al ingenio Casa Forte.

Los barrios del Conjunto Urbano de Casa Forte siguen siendo los más aristocráticos de la ciudad, en competencia directa con el metro cuadrado de Boa Viagem. Dos estilos de vida diferentes presentes en Recife.

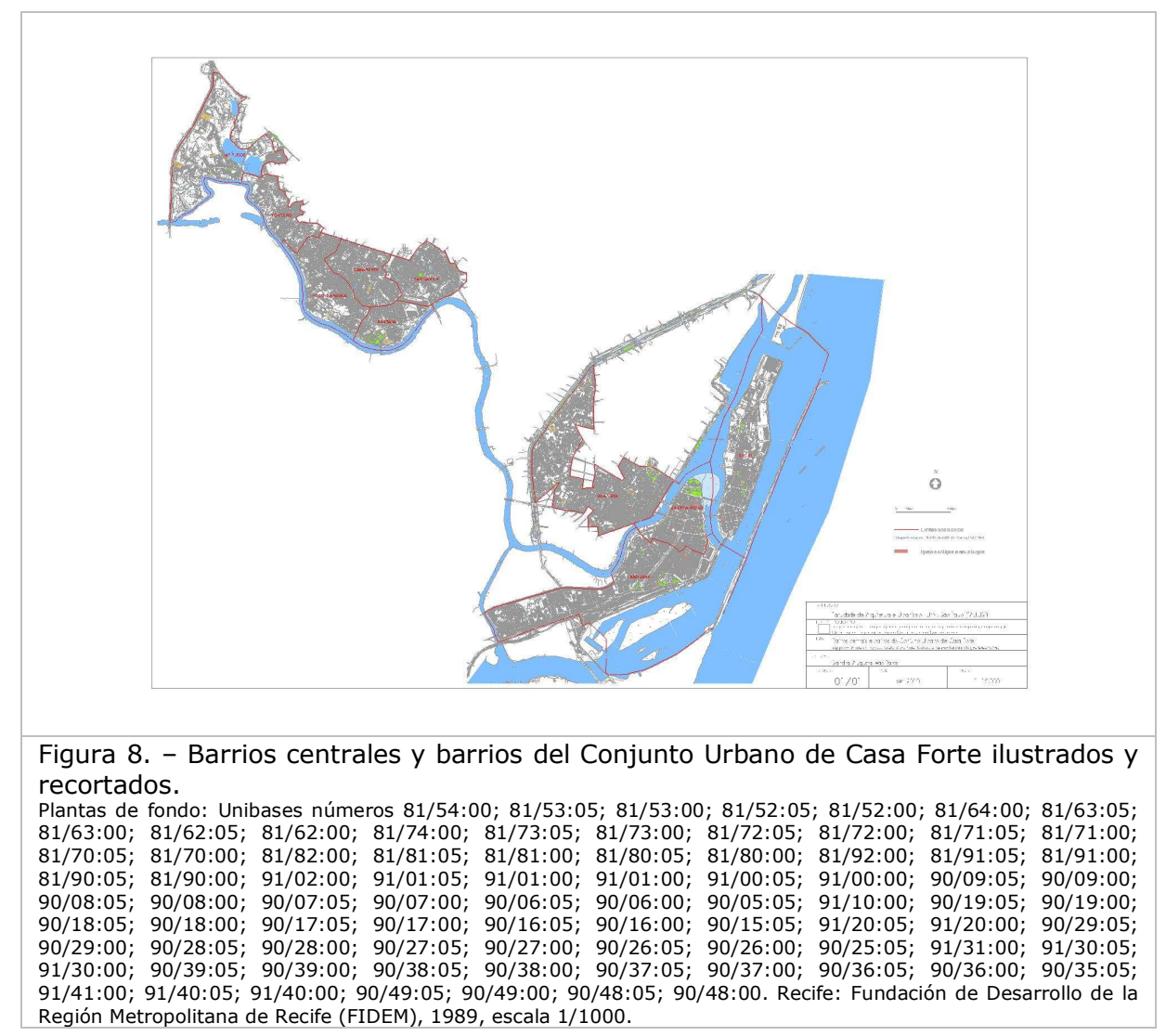

63 


\section{REVISTA DE}

\section{URBANISMO}

\section{ISSN 0717-5051}

http://revistas.uchile.cl/index.php/RU/index
Definiciones y espacialidades de barrio -arrabal, parroquia, districto y suburbio- y términos afines. Recife: los barrios centrales y del 'Conjunto Urbano de Casa Forte'

Definitions and spatialities - slum neighborhood, parish, district and suburb - and related terms. Recife: the central districts and the 'Conjunto Urbano de Casa Forte'

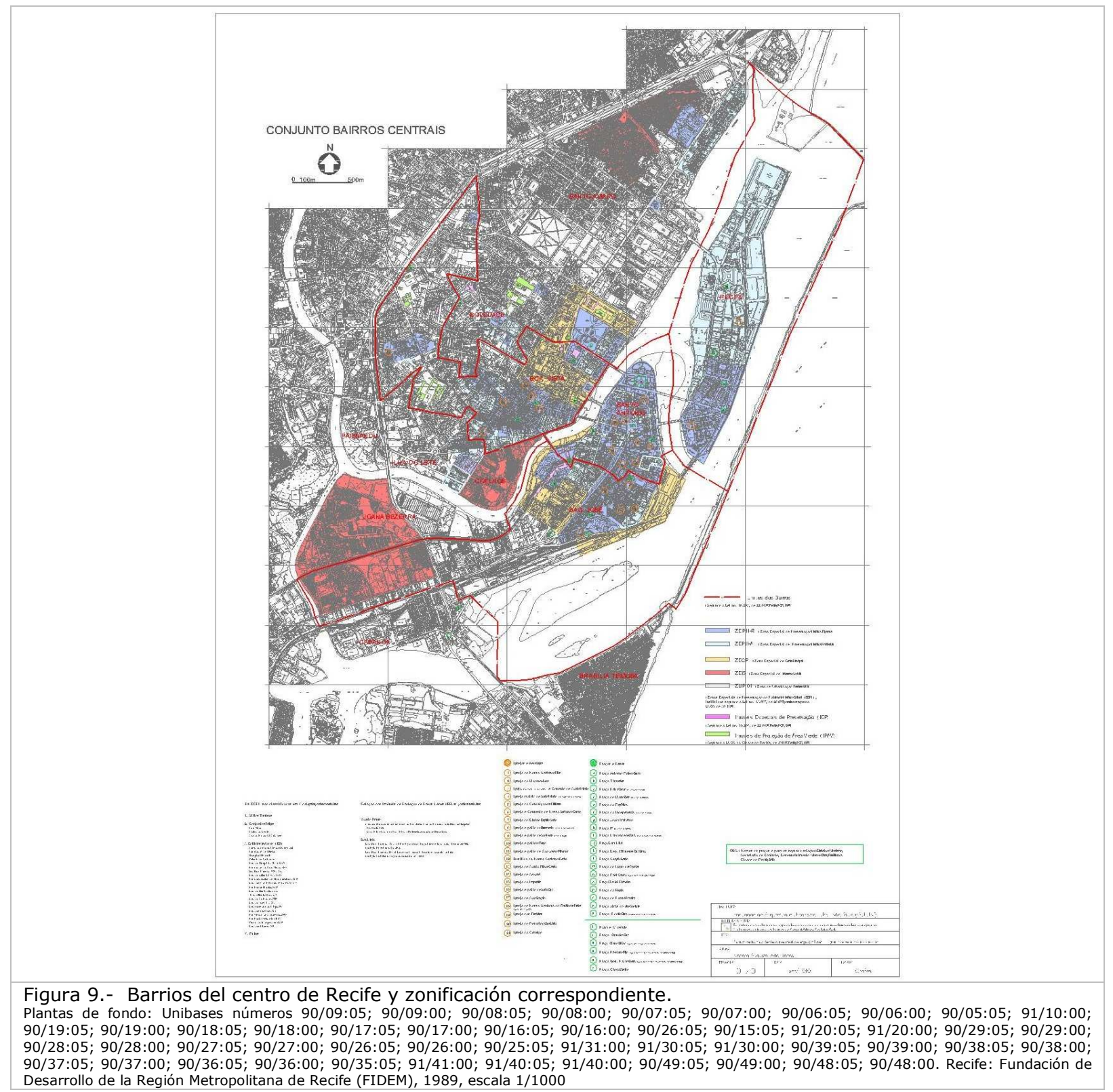




\section{REVISTA DE}

\section{URBANISMO}

ISSN 0717-5051

http://revistas.uchile.cl/index.php/RU/index
Definiciones y espacialidades de barrio -arrabal, parroquia, districto y suburbio- y términos afines. Recife: los barrios centrales y del 'Conjunto Urbano de Casa Forte'

Definitions and spatialities - slum neighborhood, parish, district and suburb - and related terms. Recife: the central districts and the 'Conjunto Urbano de Casa Forte'

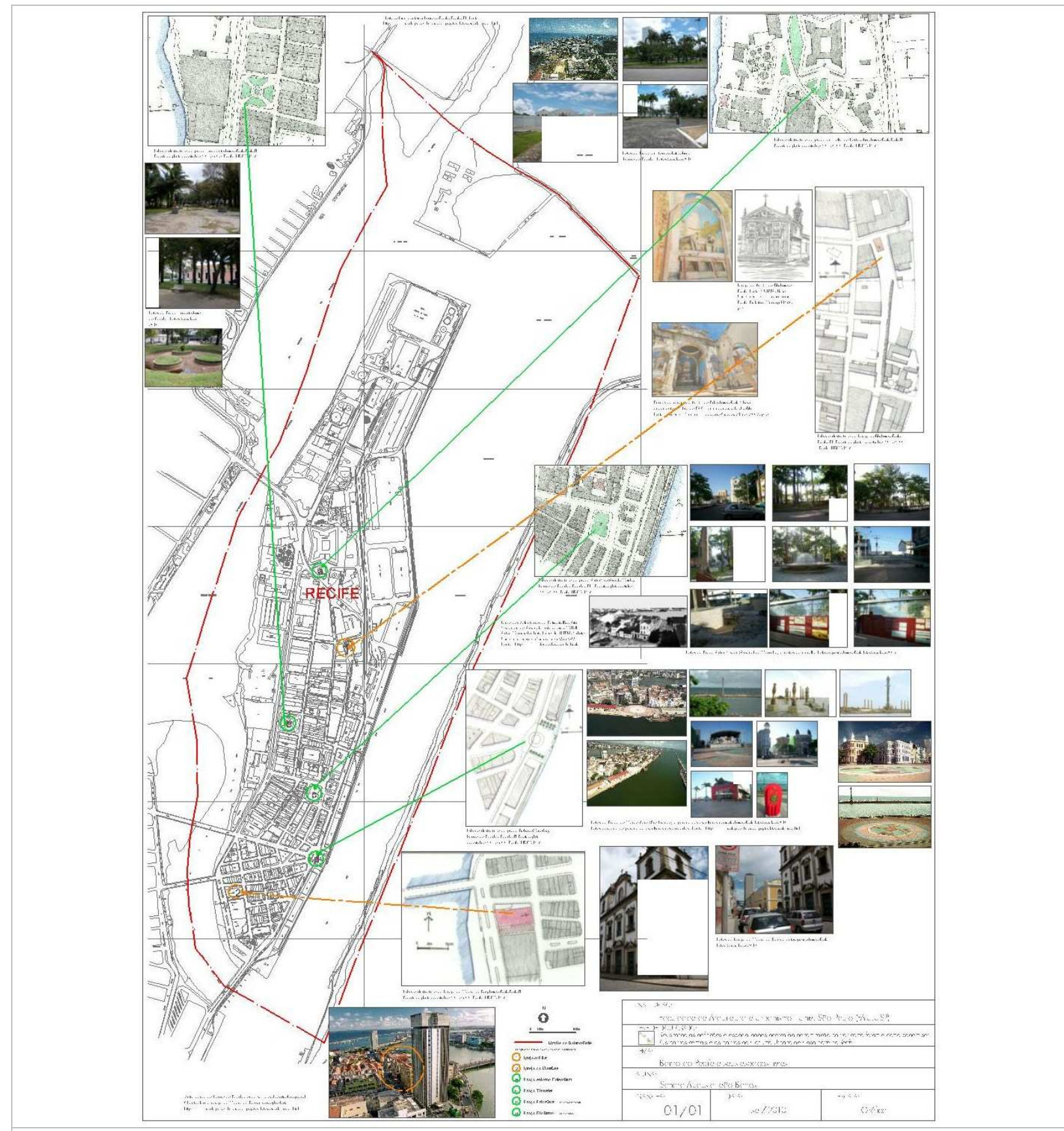

Figura 10.- Barrio del Recife y sus espacios libres.

Plantas de fondo: Unibases numeros 91/30:00; 91/30:05; 91/31:00; 90/39:05; 90/39:00; 90/38:05; 90/38:00; 90/37:05; 91/41:00; 91/40:05; 91/40:00; 90/49:05; 90/49:00; 90/48:05; 90/48:00. Recife: Fundación de Desarrollo de la Región Metropolitana de Recife (FIDEM), 1989. Escala $1 / 1000$.

65 


\section{REVISTA DE}

\section{URBANISMO}

ISSN 0717-5051

http://revistas.uchile.cl/index.php/RU/index
Definiciones y espacialidades de barrio -arrabal, parroquia, districto y suburbio- y términos afines. Recife: los barrios centrales y del 'Conjunto Urbano de Casa Forte'

Definitions and spatialities - slum neighborhood, parish, district and suburb - and related terms. Recife: the central districts and the 'Conjunto Urbano de Casa Forte'
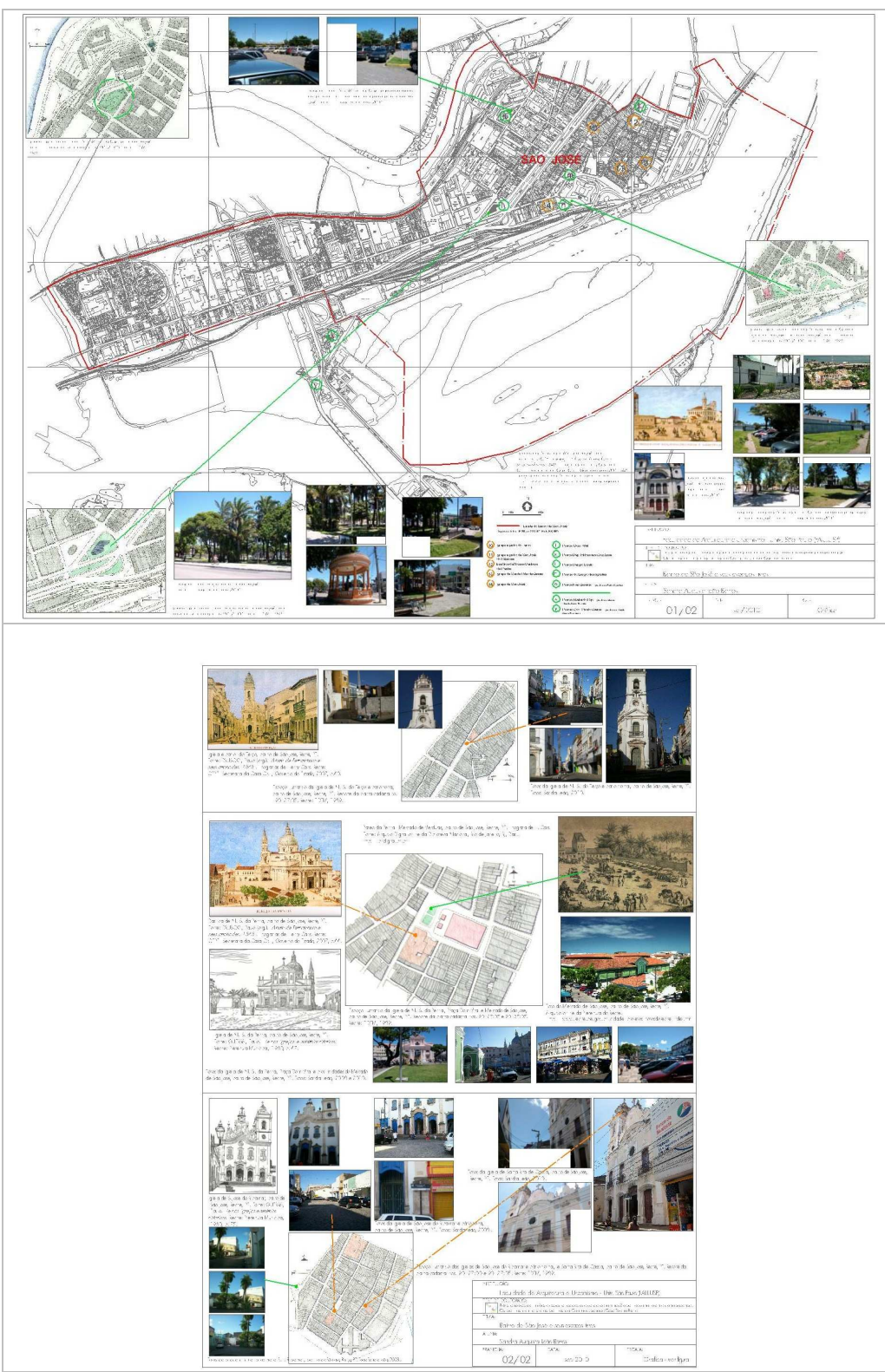

Figuras 11 y 12.- Barro de San Jose y sus espacios libres.

Plantas de fondo: Unibases numeros 90/07:05; 90/06:05; 90/06:00; 90/17:00; 90/16:05; 90/16:00 90/15:05; 90/28:00; 90/27:05; 90/27:00; 90/26:05; 90/26:00; 90/25:05; 90/37:05; 90/37:00; 90/36:05; 90/36:00. Recife: Fundación de Desarrollo de la Región Metropolitana de Recife (FIDEM), 1989, escala $1 / 1000$. 


\section{REVISTA DE}

\section{URBANISMO}

ISSN 0717-5051

http://revistas.uchile.cl/index.php/RU/index
Definiciones y espacialidades de barrio -arrabal, parroquia, districto y suburbio- y términos afines. Recife: los barrios centrales y del 'Conjunto Urbano de Casa Forte'

Definitions and spatialities - slum neighborhood, parish, district and suburb - and related terms. Recife: the central districts and the 'Conjunto Urbano de Casa Forte'

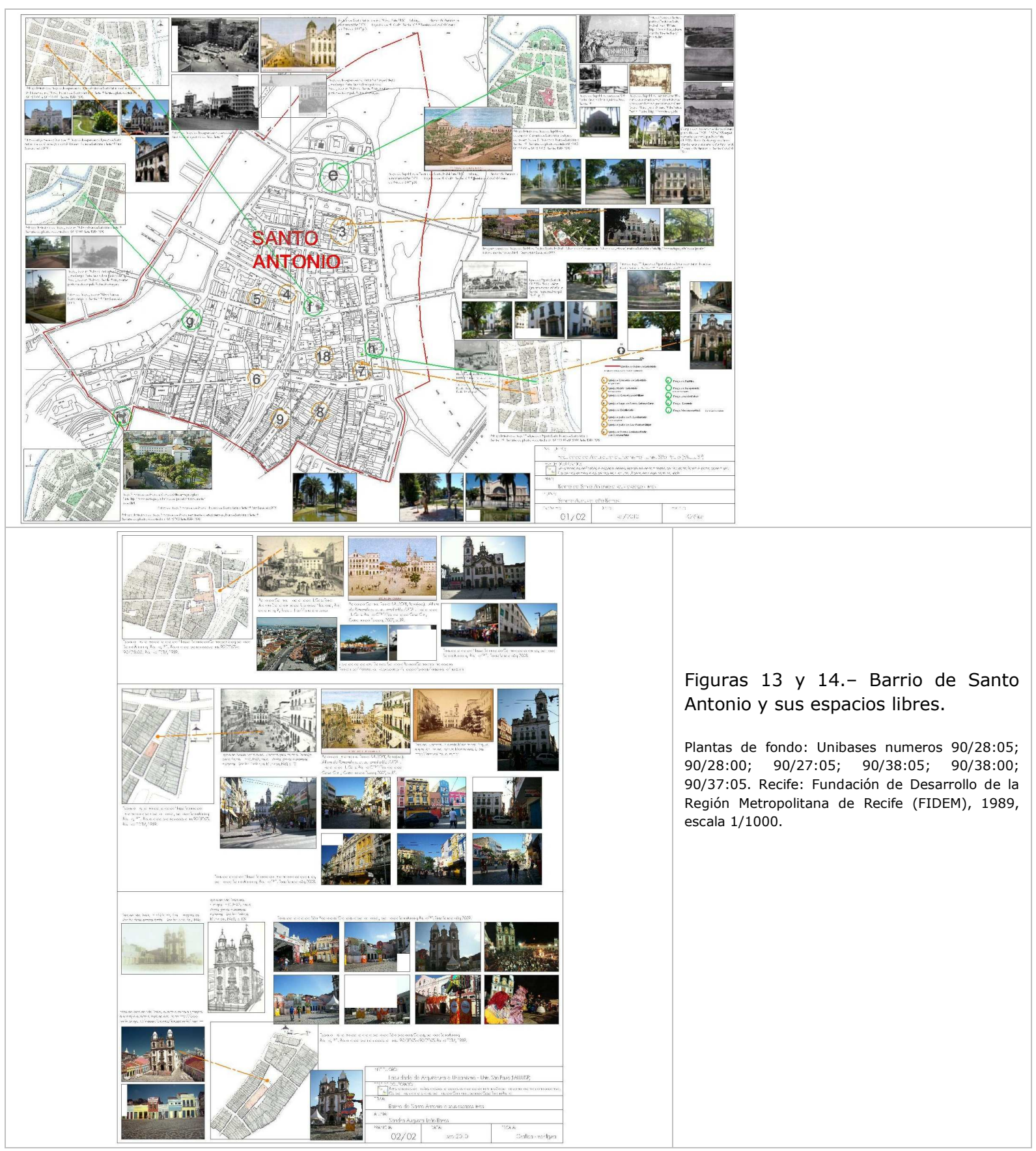

67 


\section{REVISTA DE}

\section{URBANISMO}

ISSN 0717-5051

http://revistas.uchile.cl/index.php/RU/index
Definiciones y espacialidades de barrio -arrabal, parroquia, districto y suburbio- y términos afines. Recife: los barrios centrales y del 'Conjunto Urbano de Casa Forte'

Definitions and spatialities - slum neighborhood, parish, district and suburb - and related terms. Recife: the central districts and the 'Conjunto Urbano de Casa Forte'

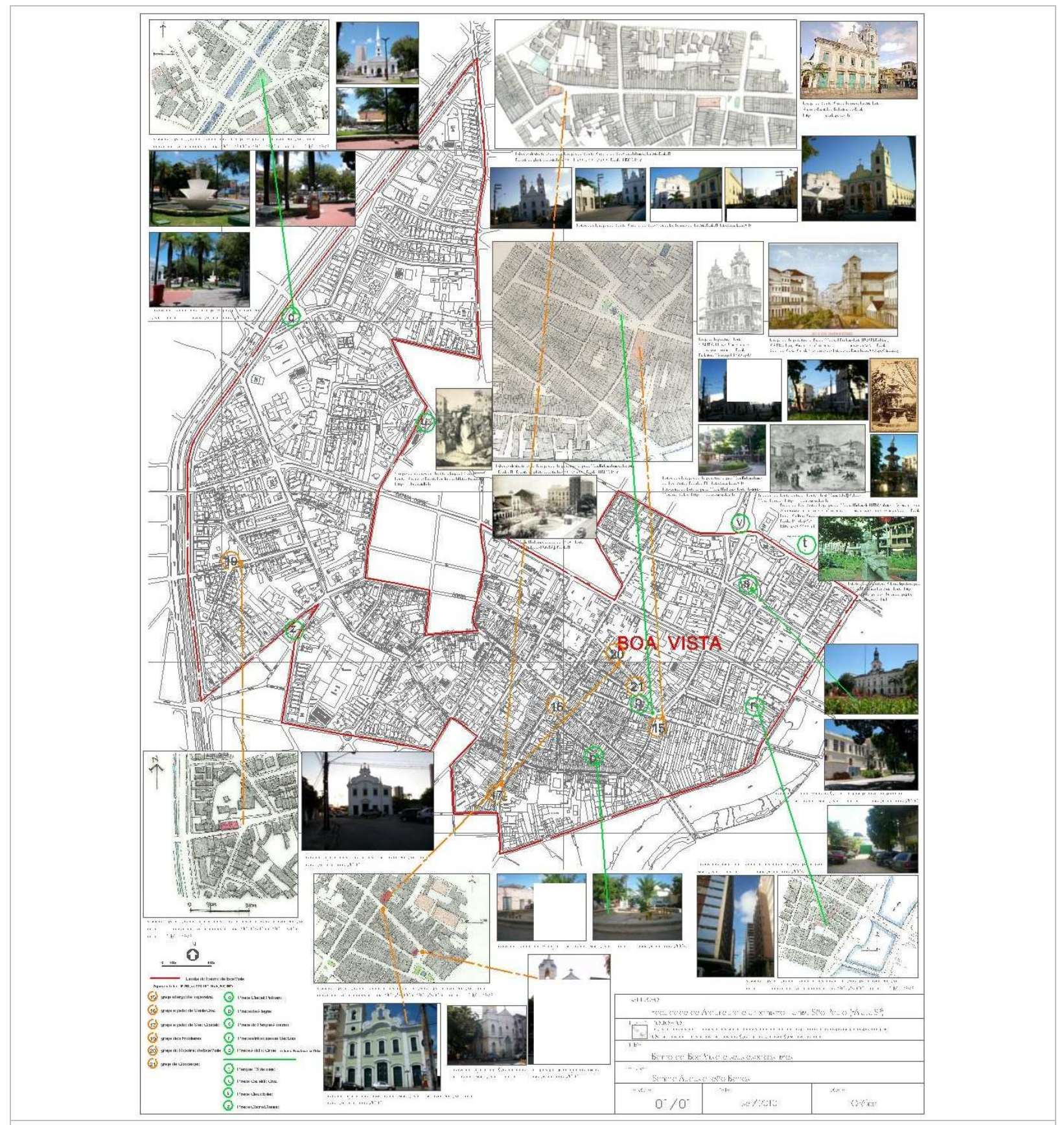

Figura 15.- Barrio de Boa Vista y sus espacios libres.

Plantas de fondo: Unibases numeros 90/09:00; 90/08:05; 90/08:00; 91/10:00; 90/19:05; 90/19:00; 90/18:05; 90/18:00; 90/17:05; 90/29:00; 90/28:05; 90/28:00; 90/27:05. Recife: Fundación de Desarrollo de la Región Metropolitana de Recife (FIDEM), 1989, escala 1/1000.

68

Revista de Urbanismo N²6 - Junio de 2012
Departamento de Urbanismo - FAU - Universidad de Chile 


\section{REVISTA DE}

\section{URBANISMO}

ISSN 0717-5051

http://revistas.uchile.cl/index.php/RU/index
Definiciones y espacialidades de barrio -arrabal, parroquia, districto y suburbio- y términos afines. Recife: los barrios centrales y del 'Conjunto Urbano de Casa Forte'

Definitions and spatialities - slum neighborhood, parish, district and suburb - and related terms. Recife: the central districts and the 'Conjunto Urbano de Casa Forte'

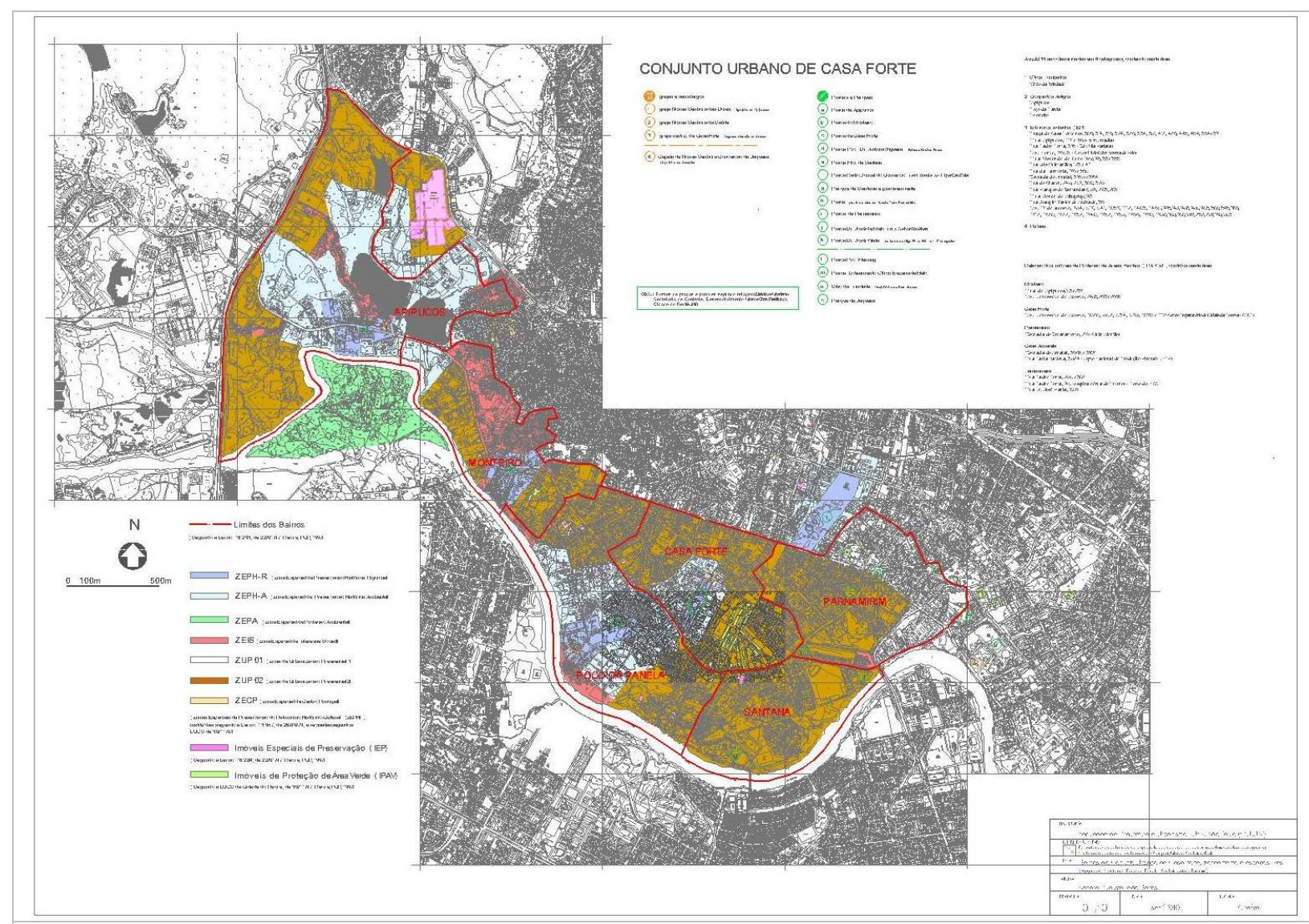

Figura 16.- Barrios del Conjunto Urbano de Casa Forte y zoneamiento correspondente.

Plantas de fondo: Unibases numeros 81/54:00; 81/53:05; 81/53:00; 81/52:05; 81/52:00; 81/64:00; 81/63:05; 81/63:00; 81/62:05; 81/62:00; 81/74:00; 81/73:05; 81/73:00; 81/72:05; 81/72:00; 81/71:05; 81/71:00; 81/70:05; 81/70:00; 81/82:00; 81/81:05; 81/81:00; 81/80:05, 81/80:00; 81/92:00; 81/91:05; 81/91:00; 81/90:05; 81/90:00; 91/02:00; 91/01:05; 91/01:00; 91/00:05; 91/00:00. Recife: Fundación de Desarrollo de la Región Metropolitana de Recife (FIDEM), 1989, escala 1/1000. 


\section{REVISTA DE}

\section{URBANISMO}

ISSN 0717-5051

http://revistas.uchile.cl/index.php/RU/index
Definiciones y espacialidades de barrio -arrabal, parroquia, districto y suburbio- y términos afines. Recife: los barrios centrales y del 'Conjunto Urbano de Casa Forte'

Definitions and spatialities - slum neighborhood, parish, district and suburb - and related terms. Recife: the central districts and the 'Conjunto Urbano de Casa Forte'

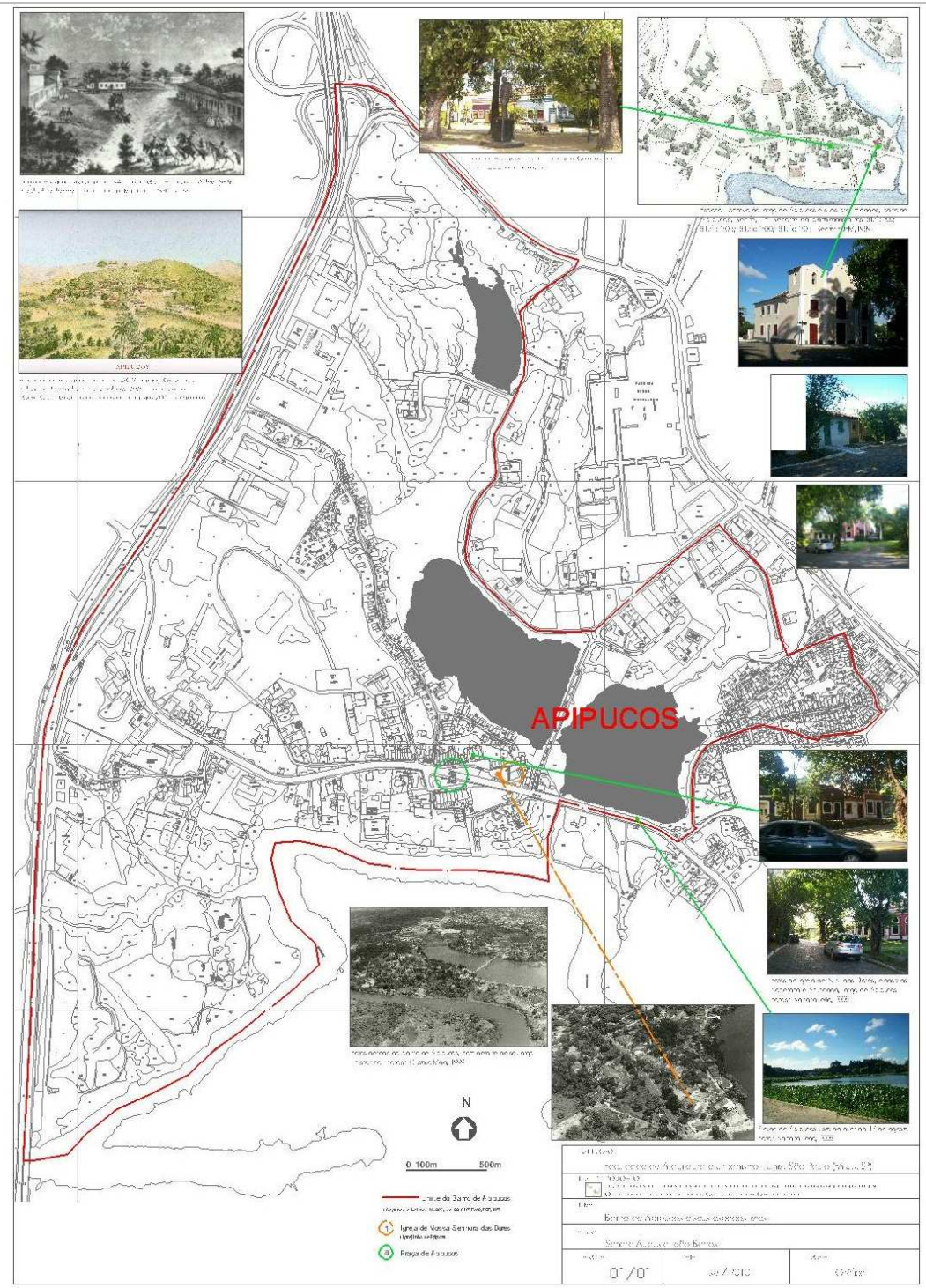

Figura 17.- Barrio de Apipucos y sus espacios libres.

Plantas de fondo: Unibases numeros 81/52:00; 81/52:05; 81/53:00; 81/62:00; 81/62:05; 81/63:00; 81/63:05; 81/64:00; 81/73:00; 81/72:05. Recife: Fundación de Desarrollo de la Región Metropolitana de Recife (FIDEM), 1989, escala 1/1000. 


\section{REVISTA DE}

\section{URBANISMO}

ISSN 0717-5051

http://revistas.uchile.cl/index.php/RU/index
Definiciones y espacialidades de barrio - arrabal, parroquia, districto y suburbio- y términos afines. Recife: los barrios centrales y del 'Conjunto Urbano de Casa Forte'

Definitions and spatialities - slum neighborhood, parish, district and suburb - and related terms. Recife: the central districts and the 'Conjunto Urbano de Casa Forte'

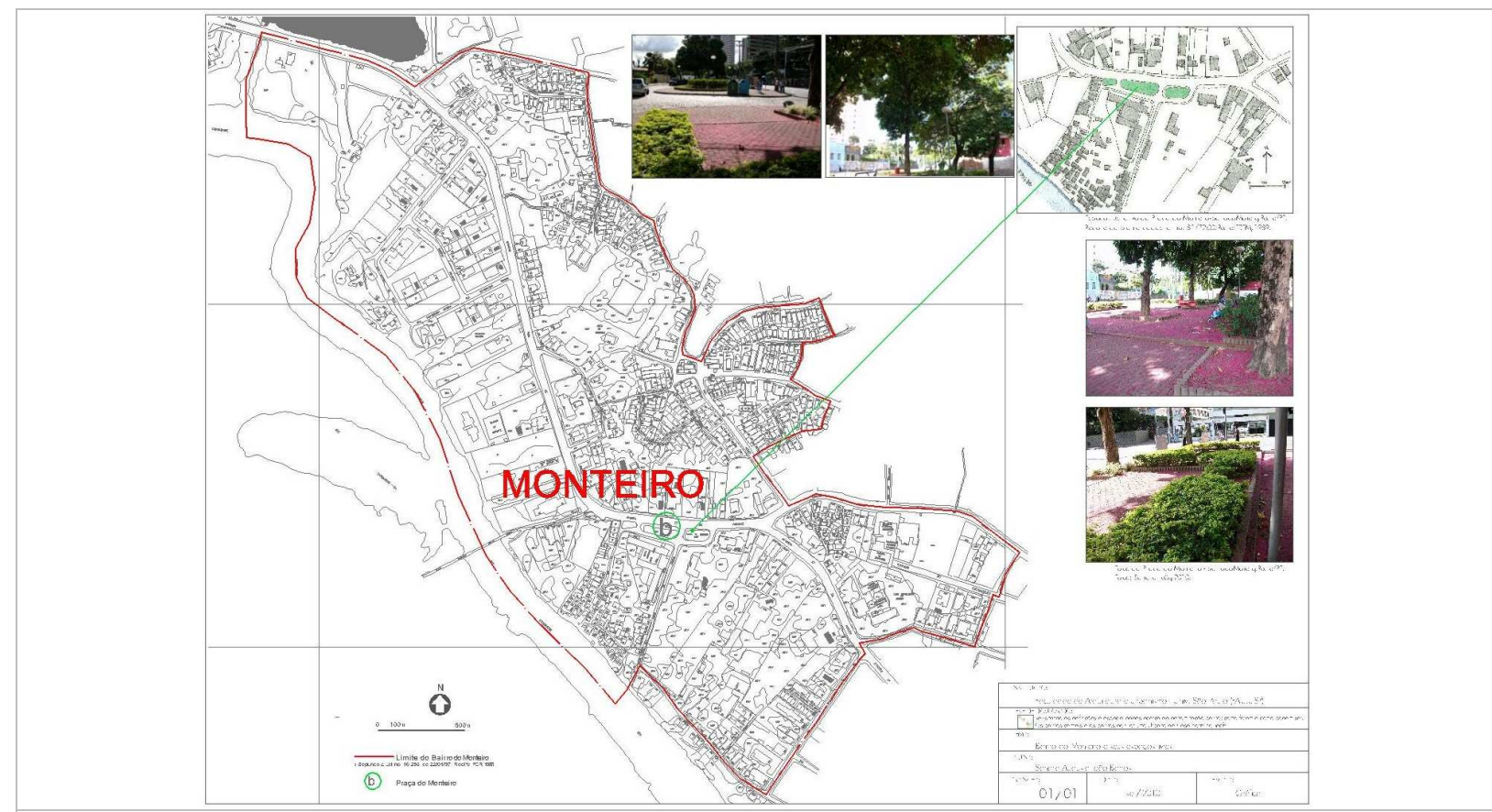

Figura 18. -Barrio de Monteiro y sus espacios libres.

Plantas de fondo: Unibases numeros 81/62:00; 81/62:05; 81/72:05; 81/72:00; 81/71:05; 81/82:00. Recife: Fundación de Desarrollo de la Región Metropolitana de Recife (FIDEM), 1989, escala 1/1000. 


\section{REVISTA DE}

\section{URBANISMO}

ISSN 0717-5051

http://revistas.uchile.cl/index.php/RU/index
Definiciones y espacialidades de barrio -arrabal, parroquia, districto y suburbio- y términos afines. Recife: los barrios centrales y del 'Conjunto Urbano de Casa Forte'

Definitions and spatialities - slum neighborhood, parish, district and suburb - and related terms. Recife: the central districts and the 'Conjunto Urbano de Casa Forte'

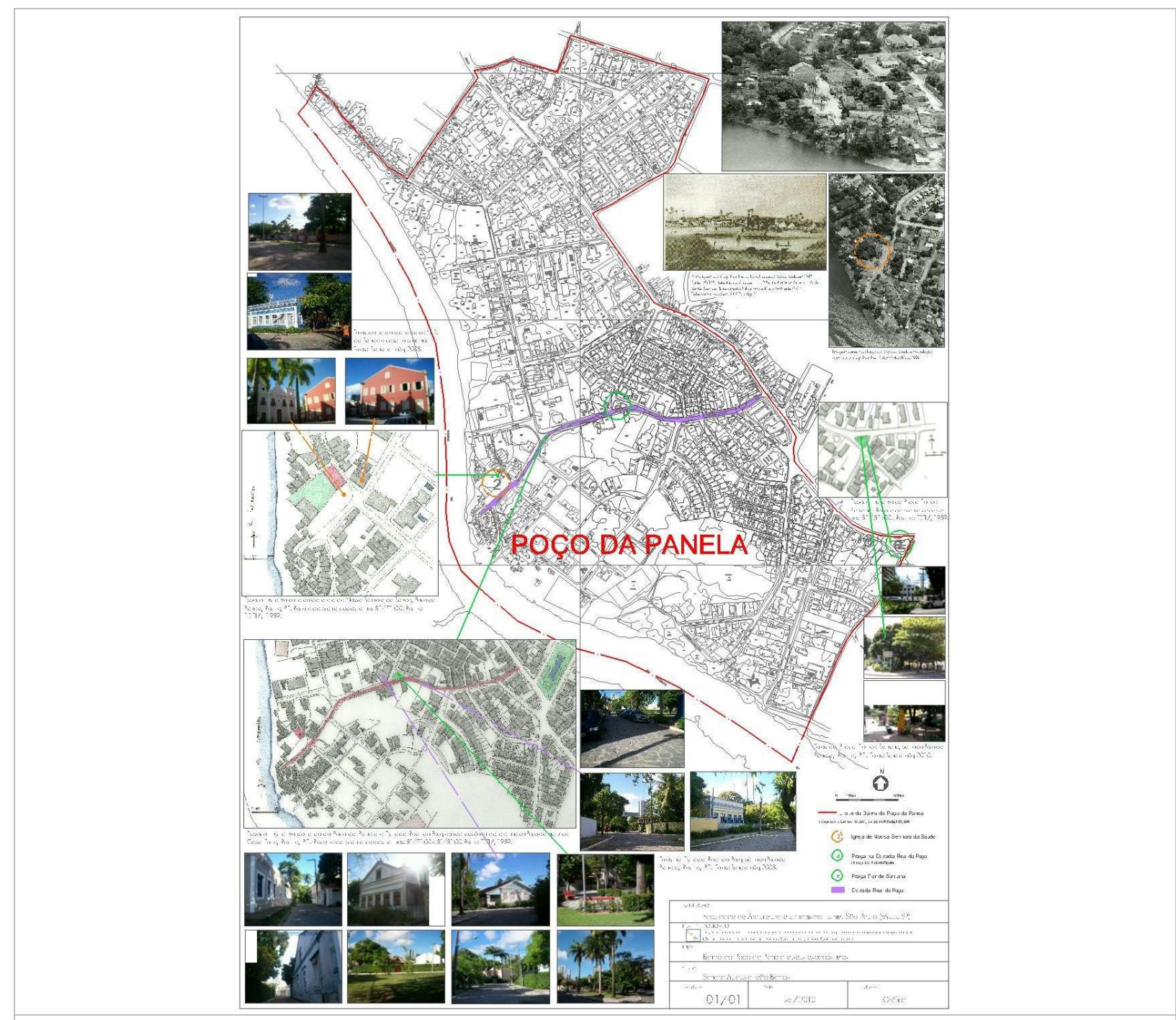

Figura 19. - Barrio de Poço da Panela y sus espacios libres.

Plantas de fondo: Unibases numeros 81/81:05; 81/81:00; 81/82:00; 81/80:05; 81/70:05; 81/71:00; 81/71:05; 81/72:00. Recife: Fundación de Desarrollo de la Región Metropolitana de Recife (FIDEM), 1989, escala 1/1000. 


\section{REVISTA DE}

\section{URBANISMO}

ISSN 0717-5051

http://revistas.uchile.cl/index.php/RU/index
Definiciones y espacialidades de barrio -arrabal, parroquia, districto y suburbio- y términos afines. Recife: los barrios centrales y del 'Conjunto Urbano de Casa Forte'

Definitions and spatialities - slum neighborhood, parish, district and suburb - and related terms. Recife: the central districts and the 'Conjunto Urbano de Casa Forte'

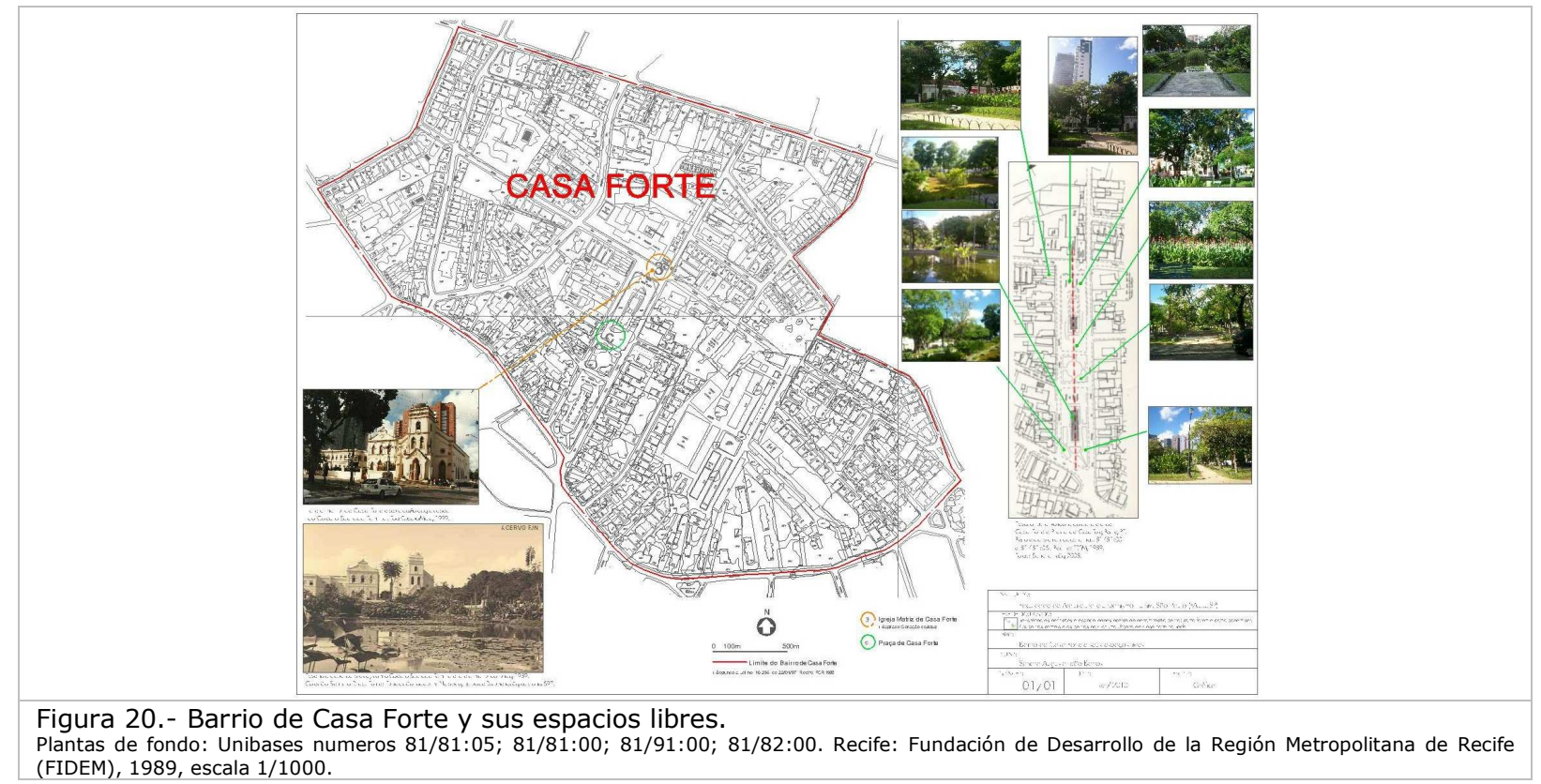
(FIDEM), 1989, escala $1 / 1000$.

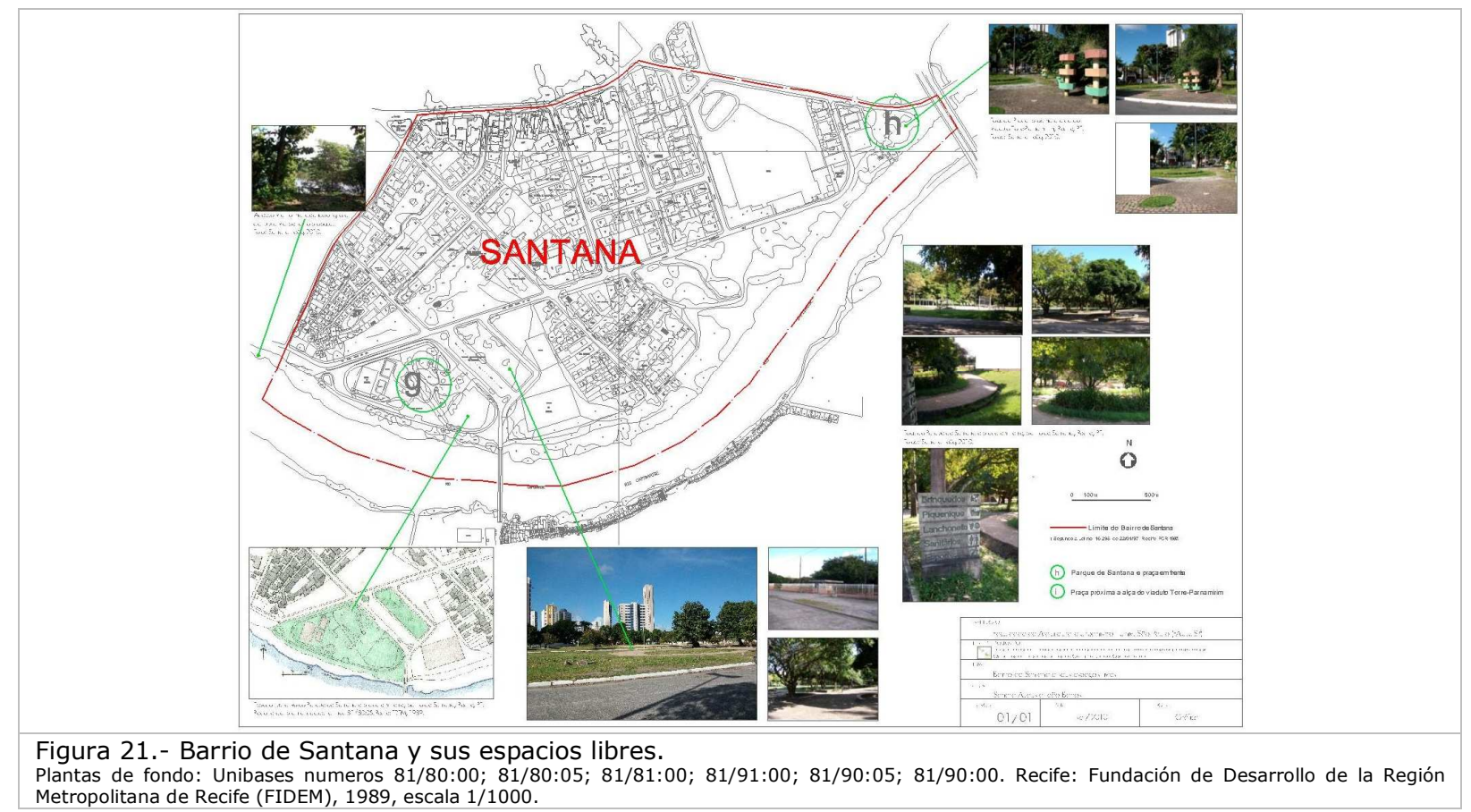

Metropolitana de Recife (FIDEM), 1989, escala 1/1000. 


\section{REVISTA DE}

\section{URBANISMO}

ISSN 0717-5051

http://revistas.uchile.cl/index.php/RU/index
Definiciones y espacialidades de barrio -arrabal, parroquia, districto y suburbio- y términos afines. Recife: los barrios centrales y del 'Conjunto Urbano de Casa Forte'

Definitions and spatialities - slum neighborhood, parish, district and suburb - and related terms. Recife: the central districts and the 'Conjunto Urbano de Casa Forte'

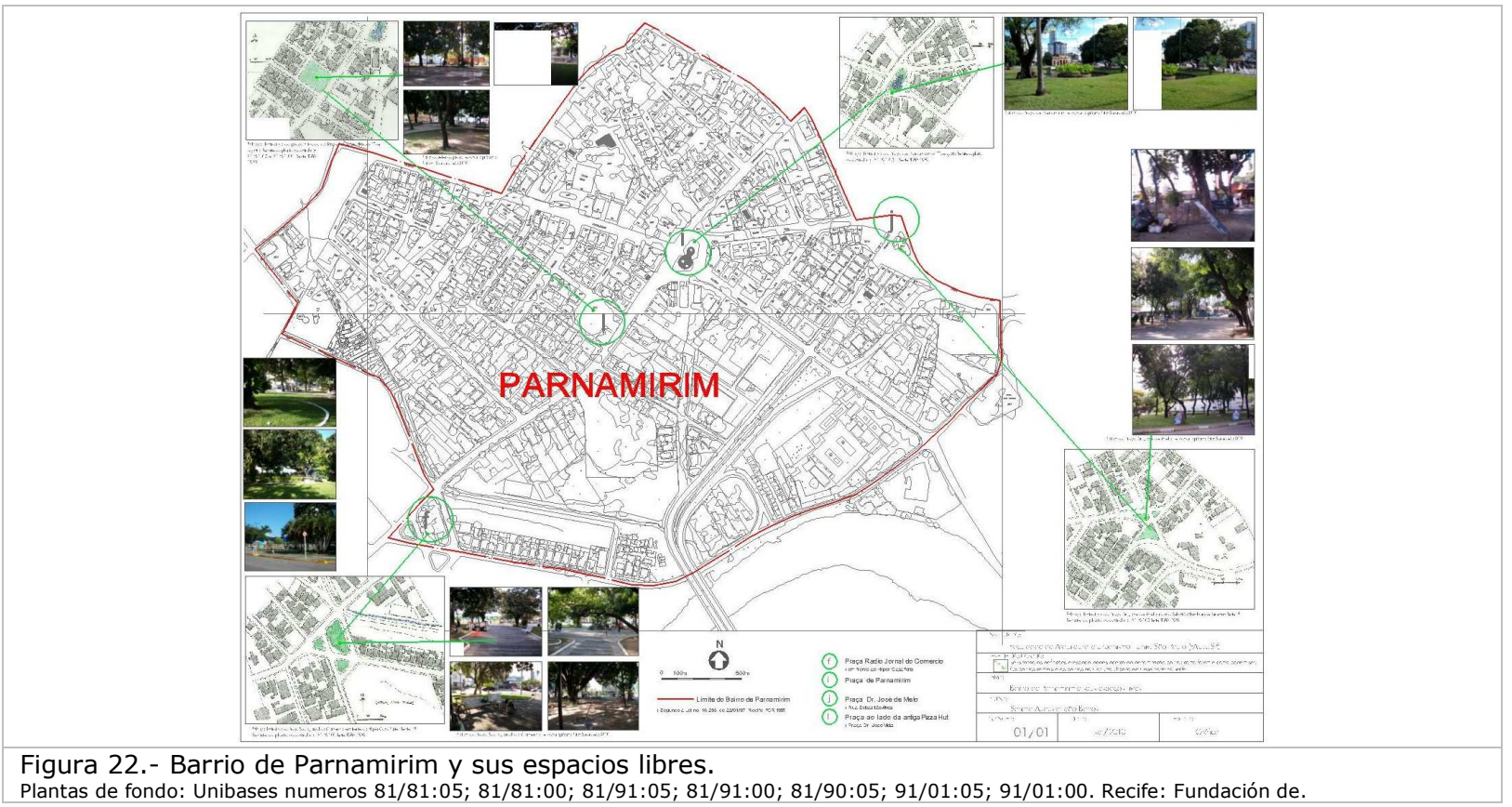

\section{Consideraciones finales}

Discutir el universo barrio es tema muy amplio y de varios grados de complejidad. Un barrio, cualquier barrio, posee un nombre, una población, un límite físico-espacial, espacios libres y espacios edificados, una forma, un contenido, una escala. Algunos atributos naturales - un río, un brazo de mar, matas, acidentes geográficos, partes planas o inclinadas. La organización y cantidad de esos ingredientes van a dar la receta, el barrio, el que nunca será igual a otro. Cada barrio es único, así como cada paisaje es único, y en permanente movimiento y transformación.

Es también el módulo sociológico y espacial de una ciudad, principalmente si estamos hablando de tejidos urbanos históricos, donde la iglesia y su patio eran el punto focal de la parroquia o feligresía de otrora. El barrio también sirvió como modulo militar, y en la actualidad, sirve como unidad del planeamiento urbano. Escala que también importante en la dimensión política del activismo de barrio, siendo más facil para sus habitantes reconocer sus centralidades, y no sus líneas.

Podemos agruparlos en comunas, como en Buenos Aires, en arrondissements, como en París, en Regiones Político-Administrativas, como en Recife. En Lisboa, nuestro sentido de barrio equivale al de parroquia. El barrio para ellos corresponde a un conjunto de parroquias. O sea, barrio A, lugar de la parroquia de .....; yo vivo en la parroquia de Santa ..., o Nuestra Señora ...., $1^{\circ}$ barrio. Es curioso que no se tenga asumida esta conotación en Brasil. Mientras sigan existindo los límites eclesiásticos de actuación de las parroquias, los barrios y sus límites siguen divisiones administrativas con otras conotaciones que se sobreponen a las iniciales, determinadas por la iglesia.

En Recife los barrios centrales siguen consolidados desde el siglo XVII, con el plan urbanístico de los holandeses, y aún hayan sufrido rellenos y cambios en altura y fachadas, todavía conservan gran parte 
REVISTA DE

URBANISMO

ISSN 0717-5051

http://revistas.uchile.cl/index.php/RU/index
Definiciones y espacialidades de barrio -arrabal, parroquia, districto y suburbio- y términos afines. Recife: los barrios centrales y del 'Conjunto Urbano de Casa Forte'

Definitions and spatialities - slum neighborhood, parish, district and suburb - and related terms. Recife: the central districts and the 'Conjunto Urbano de Casa Forte'

de su división inicial. El crecimiento en dirección al interior de la costa se hizo por medio de 'ganglios', que correspondían otrora a los ingenios de azúcar, los cuales, con el advenimiento de su ferrovía, pasan a ser llamados de arrabales, alrededores, suburbios históricos.

Este trabajo buscó otras formas de mirar los barrios. El lado histórico ofrece, por cierto, pistas claras y concisas sobre la identidad de la propia ciudad a que pertenencen. Una identidad hasta cierto punto bipolar en el caso de Recife: centro - suburbios históricos, o centro - tierra baja, diferente y única entre sus similares en el Nordeste de Brasil.

\section{Bibliografía}

BOSI, Alfredo. Dialética de la colonización. São Paulo: Compañia de las Letras, 1994. ISBN 85-7164-276-1.

BRUSCKY, Paulo (org.). Album de Pernambuco y sus arrabales: 1878. Litografias de F. H. Carls, Ed. Fac-Similada y ampliada. Recife: CEPE, Secretaria de la Casa Civil, Gobierno del Estado, 2007.

CAMPOS FILHO, Candido Malta. Reinventar su barrio: caminos para usted participar del planeamiento de su ciudad. São Paulo: Editora 34, 2003. ISBN 85-7326-268-0.

CANDIDO, Antonio. Los parceros del Rio Bonito: estudios sobre el caipira paulista y los cambios de sus medios de vida. São Paulo: José Olympio Editora, 1964 (2001 reedición).

CARLOS, Ana Fani Alessandri. El lugar en/del mundo. São Paulo: Hucitec, 1996. ISBN 85-271-0368-0.

CASTRO, Josué de. Un ensayo de Geografia Urbana: la Ciudad de Recife. In: Ensayos de Geografia Humana. São Paulo: Brasiliense, 1957, p. 193-280.

CAVALCANTI, Carlos Bezerra. El Recife y sus barrios. Recife: Camara Municipal del Recife, 2002. ISBN 85-902543$1-3$.

CAZZOLATO, José Donizete. Los barrios como instancia territorial local: contribución metodológica para el caso de San Pablo. 2005. 159f. Monografía (Master en Geografia) - Facultad de Filosofia, Letras y Ciencias Humanas, Universidad de São Paulo, São Paulo, 2005.

COSTA, Pereira da. Alrededores del Recife. Recife: Massangana (Fundaj), 2001. ISBN 85-7019-3815.

GUERRA, Flavio. Viejas iglesias y suburbios históricos. Recife: Ayuntamiento Municipal del Recife, 1960.

LAMAS, José Ressano Garcia. Morfologia urbana y diseño de la ciudad. Lisboa: Fundación Calouste Gulbekian, 1993. ISBN 972-31-0606-x.

LEFEBVRE, Henri. De lo rural a lo urbano. Barcelona: Ediciones Península, 1971, p. 195-203. ISBN 84-2970-910x.

MARX, Murillo de Azevedo. Ciudad en Brasil: tierra de quién? São Paulo: Edusp, 1980. ISBN 85-2130-6504.

MELLO, José Antonio Gonsalves de. Tiempo de los flamengos: influencia de la ocupación holandesa em la vida y em la cultura del norte de Brasil. Rio de Janeiro: Topbooks, 2007. ISBN 85-7475-035-2.

MENEZES, José Luiz da Mota. Atlas cartográfico del Recife. Recife: Massangana (Fundaj)/Empresa de Urbanización del Recife (URB), 1988. ISBN 85-7019-172-3.

MORRIS, Anthony E. J. Historia de la forma urbana: desde sus orígenes hasta la Revolución Industrial. Barcelona: Gustavo Gilli, 1979. ISBN 84-2521-1816.

RAPOPORT, Amos. Aspectos humanos de la forma urbana: hacia una confrontación de las Ciencias Sociales con el diseño de la forma urbana. Barcelona: Gustavo Gili, 1978, p. 163. ISBN 84-252-0718-5. 


\section{REVISTA DE}

\section{URBANISMO}

ISSN 0717-5051

http://revistas.uchile.cl/index.php/RU/index
Definiciones y espacialidades de barrio -arrabal, parroquia, districto y suburbio- y términos afines. Recife: los barrios centrales y del 'Conjunto Urbano de Casa Forte'

Definitions and spatialities - slum neighborhood, parish, district and suburb - and related terms. Recife: the central districts and the 'Conjunto Urbano de Casa Forte'

REIS FILHO, Nestor Goulart. Contribución al estudio de la evolución urbana en Brasil: 1500-1720. São Paulo: Pini, 2000. ISBN 85-7266-1166.

RECIFE, Prefeitura da Cidade do. Atlas Ambiental de la Ciudad de Recife. Recife: Secretaria de Planeamiento, Urbanismo y Medio Ambiente, 2000. facículos).

El Recife: historias de una ciudad. Recife: Jornal do Commercio, BCP Telecomunicaciones, 2000 (10

Ley $\mathrm{n}^{\circ} .16 .284$, de 22 de janeiro de 1997. Dispone sobre los Imuebles Especiales de Preservación (IEP). Recife: Secretaria de Planeamiento, Urbanismo y Medio Ambiente, 1997.

. Ley de Uso y Ocupación del Suelo de la Ciudad de Recife, de 30 de enero de 1997. Planchas ns. 81/52:05; 81/50:00; 81/70:50; 91/20:50; 90/07:05; 90/05:00; 90/25:50; 90/27:55. Recife: Secretaria de Planeamiento Urbanismo y Medio Ambiente, 1997. Escala gráfica. Disponible en: <http://www.recife.pe.gov.br/pr/leis/luos/soloZEPH.html>. Aceso en: oct. 2010.

Ley $\mathrm{n}^{\circ}$. 16.293, de 22 de enero de 1997. Dispone sobre las Regiones Político-Administrativas del Municipio de Recife. Recife: Secretaria de Planeamiento, Urbanismo y Medio Ambiente, 1997.

Atlas Metropolitano: Desarrollo Humano de la Región Metropolitana de Recife. Recife: Agencia Condepe/Fidem, Secretaria de Planeamiento, PNUD, 2010.

SÁ CARNEIRO, Ana Rita; MESQUITA, Liana de Barros (orgs.). Espacios libres de Recife. Recife: Ayuntamiento Municipal del Recife, UFPE, 2000.

SANTOS, Carlos Nelson dos. La ciudad como un juego de cartas. Niterói: Eduff; São Paulo: Projeto, 1988. ISBN 857165-001-2.

SANTOS, Paulo Ferreira. Formación de ciudades en el Brasil Colonial. Rio de Janeiro: Editora UFRJ, 2001. ISBN 857108-228-6.

SOUZA, Marcelo José Lopes de. El barrio contemporáneo: ensayo de abordaje política. Revista Brasilera de Geografia. Rio de Janeiro, n. 51, p. 139-172, 1989.

TEIXEIRA, Manuel C. (org.). La plaza en la ciudad portuguesa. Lisboa: Libros Horizonte, 2001. ISBN 97-2241-1209.

VERA, Luis Cervera. Plazas mayores de España. Madrid: Espasa-Calpe, 1990, p. 9-41, v. 1. ISBN 84-239-5285-1.

VITERBO, Frei Joaquim de Santa Rosa de. Elucidário de las palabras, términos y frases, que en Portuga antigamente se usaron y que hoy regularmente se ignoran. $2^{a}$ edição. Lisboa: Libreria Civilización, 1865, v. 1, p. 573.

WILHEIM, Jorge. Proyecto São Paulo: propuestas para la mejoría de la vida urbana. Rio de Janeiro: Paz y Tierra, 1982 , p. 63-80 (el barrio, unidad urbana). 